\title{
Malignant adnexal neoplasms
}

\author{
A Neil Crowson ${ }^{1}$, Cynthia M Magro² and Martin C Mihm³ \\ ${ }^{1}$ Departments of Dermatology, Pathology, and Surgery, University of Oklahoma and Regional Medical \\ Laboratory, St John Medical Center, Tulsa, OK, USA; ${ }^{2}$ Division of Dermatopathology, Department of \\ Pathology, Ohio State University, Columbus, OH, USA and ${ }^{3}$ Departments of Dermatology and Pathology, \\ Harvard Medical School, Massachusetts General Hospital, Boston, MA, USA
}

\begin{abstract}
Malignant cutaneous adnexal neoplasms are one of the most challenging areas of dermatopathology. Tumors of the pilosebaceous apparatus can occur as single-lineage neoplasms or may manifest as complex proliferations with multilineal differentiation patterns including not only the germinative component of the hair bulb, the inner or outer root sheath epithelium and the sebaceous gland and duct, but also the sweat duct components that relate to the apocrine secretory apparatus which empties into the follicle near the follicular bulge. Eccrine and apocrine neoplasms present a bewildering array of morphologies, which often defy precise classification. The purpose of this review is to discuss in detail the malignant neoplasms of the cutaneous adnexae and their benign and prognostically indeterminate mimics.

Modern Pathology (2006) 19, S93-S126. doi:10.1038/modpathol.3800511
\end{abstract}

Keywords: eccrine carcinoma; sebaceous neoplasia

\section{Malignant tumors of the pilosebaceous apparatus, their mimics and precursors}

\section{Introduction}

Tumors of the pilosebaceous unit can occur in isolation or in combination with complex proliferations showing multilineal differentiation patterns encompassing those of sweat ducts, epidermis and stroma with its varied components. In this review, we will focus upon the malignant adnexal proliferations, considering benign entities mainly insofar as they impact the diagnostic approach to adnexal carcinoma. We will first turn to the malignant sebaceous neoplasms, their precursors and their mimics.

\section{Sebaceous adenoma}

\section{Clinical Features}

The sebaceous adenoma is a benign neoplasm that manifests clinically as a pale yellow nodular lesion, typically of the face, that expresses itself clinically after the age of 50 . Tumors range in size from $<1$ to $>5 \mathrm{~cm} .{ }^{1-6}$ These lesions are associated with the

Correspondence: Dr AN Crowson, MD, Regional Medical Laboratory, St John Medical Center, 1923 S Utica Street, Tulsa, OK 74114-4109, USA.

E-mail: ncrowson@sjmc.org

Received 16 September 2005; accepted 28 September 2005
Muir-Torre syndrome, comprising the coexpression of cutaneous neoplasms, including those of sebaceous type with well-differentiated squamous epithelial neoplasms, and visceral malignancies, including carcinomas of the breast, ovary, gastrointestinal tract and larynx. ${ }^{7-14}$ An occasional patient may manifest a malignant lymphoma of nodal or extranodal type. ${ }^{10,12,14}$ Sebaceous neoplasms in the setting of Muir-Torre syndrome are often difficult to classify, showing overlap features between all of the prototypic forms of sebaceous neoplasm ranging from hyperplasia to carcinoma. ${ }^{13}$

\section{Histology}

The prototypic sebaceous adenoma manifests 1-2 layers of germinitive cells which mature to form central sebocytes, and have an architecture comprising a sharply circumscribed sebaceous lobule surrounded by a compressed pseudocapsule of dermal stroma (Figure 1a). The overlying epidermis may be attenuated, but sometimes forms a collarette around the peripheral aspect of the neoplasm. Unlike sebaceous hyperplasia, occasional mitoses may be seen in the lobules of a sebaceous adenoma and in concert with this nucleoli may be somewhat prominent, but the pleomorphism, hyperchromasia and individual cell necrosis of the sebaceous epithelioma are not apparent (Figure 1b). When seen in the context of the Muir-Torre syndrome, lesions mimicking sebaceous adenoma may open 
S94

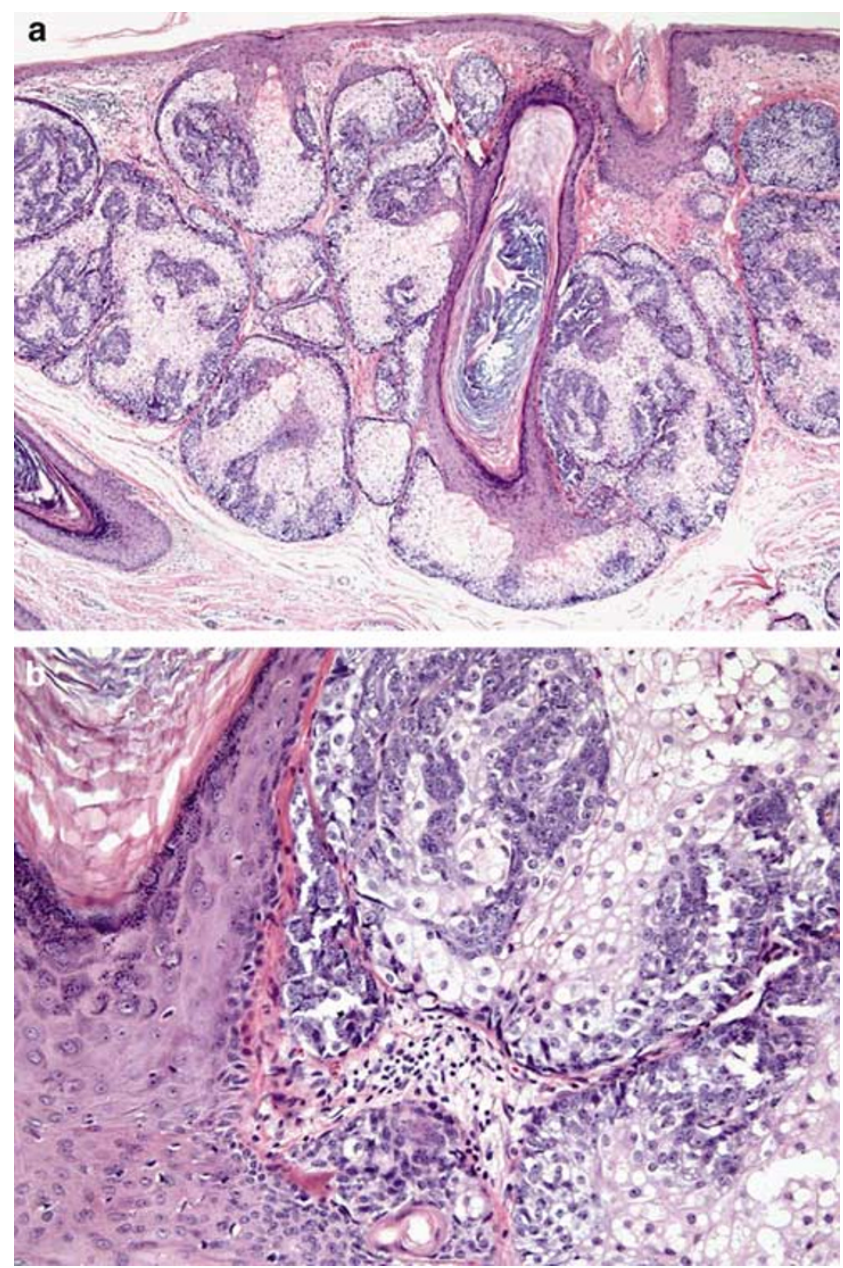

Figure 1 Sebaceous adenoma. Sebaceous adenoma comprises an admixture of germinative epithelia and sebocytes in a nodular array grouped around one or more hair follicle structures (a). Intermediate-power microscopy shows that the germinative epithelia comprise less than $50 \%$ of the diameter of the tumor lobule, but are greater than the 1-2 cell layers in thickness seen in lesions of sebaceous hyperplasia (b).

directly to the epidermal surface in a fashion that mimics nevus sebaceus.

\section{Differential Diagnosis}

The nevus sebaceus can form a confounding morphology with the sebaceous neoplasia of MuirTorre syndrome, as can the basal cell carcinoma (BCC) with sebaceous differentiation. ${ }^{15-18}$ The MuirTorre syndrome is described in detail below. Another consideration in the differential diagnosis of sebaceous adenoma is the sebaceous epithelioma. Most observers equate the term sebaceous epithelioma with a BCC, typically of nodular type, showing central sebaceous differentiation. In the sebaceous epithelioma, atypical basaloid cells mimicking the germinitive cells of sebaceous hyperplasia are identified in the periphery of tumor lobules, but fill $>50 \%$ of the diameter of individual nodules and are associated with apotosis, mitotic activity and slit-like retraction of the tumor cell nests from the adjacent stroma, accompanied by mucinotic collagen degeneration. The sebaceous adenoma in contrast has an increased number of germinitive cell layers as opposed to sebaceous hyperplasia; typically, these constitute greater than two outside layers, but less than $50 \%$ of the diameter of the tumor nodule. Individual cell necrosis, mitotic activity and slit-like retraction of stroma are not features of sebaceous adenoma. A nevus sebaceus typically shows epidermal hyperplasia with mammillation of the surface mimicking an epidermal nevus. The sebaceous lobules in nevus sebaceus are abortive, often opening directly to the epidermal surface as opposed to through the infundibular sebaceous duct of a mature hair follicle structure. In concert with this anomaly, hairs (either polarizable terminal hairs or vellus hairs) are not seen in the folliculosebaceous anlage of the nevus sebaceus. By polarized light microscopy, one can delineate the transverse margin of a nevus sebaceus when one recognizes these mature hair shafts lateral to the lesion itself. As nevus sebaceus is a hamartoma, often with a complex mesenchymal and epithelial derivation, the stroma may appear hyperplastic and ectopic apocrine glands may be present in the dermis, sometimes with a concomitant increase in blood vessels. As nevus sebaceus can give rise to basaloid proliferations including superficial BCC and its nodular and infiltrative growth derivatives, the distinction between nevus sebaceus and sebaceous hyperplasia is an important one. Finally, the nevus sebaceus can be associated with other forms of neoplasia such as syringocystadenoma papilliferum.

\section{Superficial epithelioma with sebaceous differentiation}

\section{Clinical Features}

The superficial epithelioma with sebaceous differentiation manifests as a slow-growing smooth surfaced papule or keratotic nodule on the face, trunk or thigh. ${ }^{19}$

\section{Histopathology}

The lesions mimic a tumor of follicular infundibulum or superficial BCC by virtue of anastomosing cells that connect broadly to the basal layer of epidermis and have an orientation parallel to the epidermal surface. Some examples show peripheral palisading, leading some observers to suggest that this represents a form of superficial BCC with sebaceous differentiation cognate to the sebaceous epithelioma, ${ }^{20,21}$ while other examples show squamous differentiation. 


\section{Differential Diagnosis}

The presence of sebaceous differentiation distinguishes this lesion from the inverted follicular keratosis and the prototypic superficial BCC. An exceptional example of a tumor of follicular infundibulum showing sebaceous differentiation was reported in $2001,{ }^{22}$ but these lesions show no slitlike retraction from a mucinotic stroma.

\section{Sebaceoma}

\section{Introduction}

The term sebaceoma was first introduced by Troy and Ackerman ${ }^{23}$ who described a dermal sebaceous neoplasm having histological overlap features of sebaceous adenoma and sebaceous epithelioma.

\section{Histopathology}

These sharply circumscribed lesions have smooth borders and asymmetry, and comprise aggregates of undifferentiated basaloid cells admixed with vacuolated sebocytes and sebaceous ducts (Figure 2a and b). The latter may contribute, through metaplastic change, squamous epithelia to the nodules. These components are admixed in an often haphazard fashion. ${ }^{24}$ The proportions of these components vary and have no set definition. Holocrine secretion may generate necrosis en masse, but necrosis of the tumor cells themselves is never conspicuous. ${ }^{24-26}$ There is a verrucous or seborrheic keratosis-type lesion in which the sebaceous components connect to a hyperplastic epidermis through a proliferation of infundibular keratinocytes. ${ }^{24}$

\section{BCC with sebaceous differentiation (sebaceous epithelioma)}

\section{Histopathology}

As mentioned above, the BCC with sebaceous differentiation, a term equated by some authors and by us to sebaceous epithelioma, ${ }^{27}$ is typically a form of nodular BCC showing slit-like retraction of tumor from a mucinotic stroma with $>50 \%$ of the tumor lobule comprising germinitive basaloid cells, which demonstrate individual cell necrosis and mitotic activity (Figure 3a and b). ${ }^{15-18}$ Although the cells have a homology with the germinitive cells of sebaceous adenoma, they tend to be larger with more open nuclei and more prominent nucleoli and the finding of slit-like retraction, although demonstrable in most if not all lesions and a principal defining feature, may be focal and difficult to identify in any particular tumor. Unlike sebaceous carcinoma, these tumors do not manifest pagetoid spread through the overlying epidermis
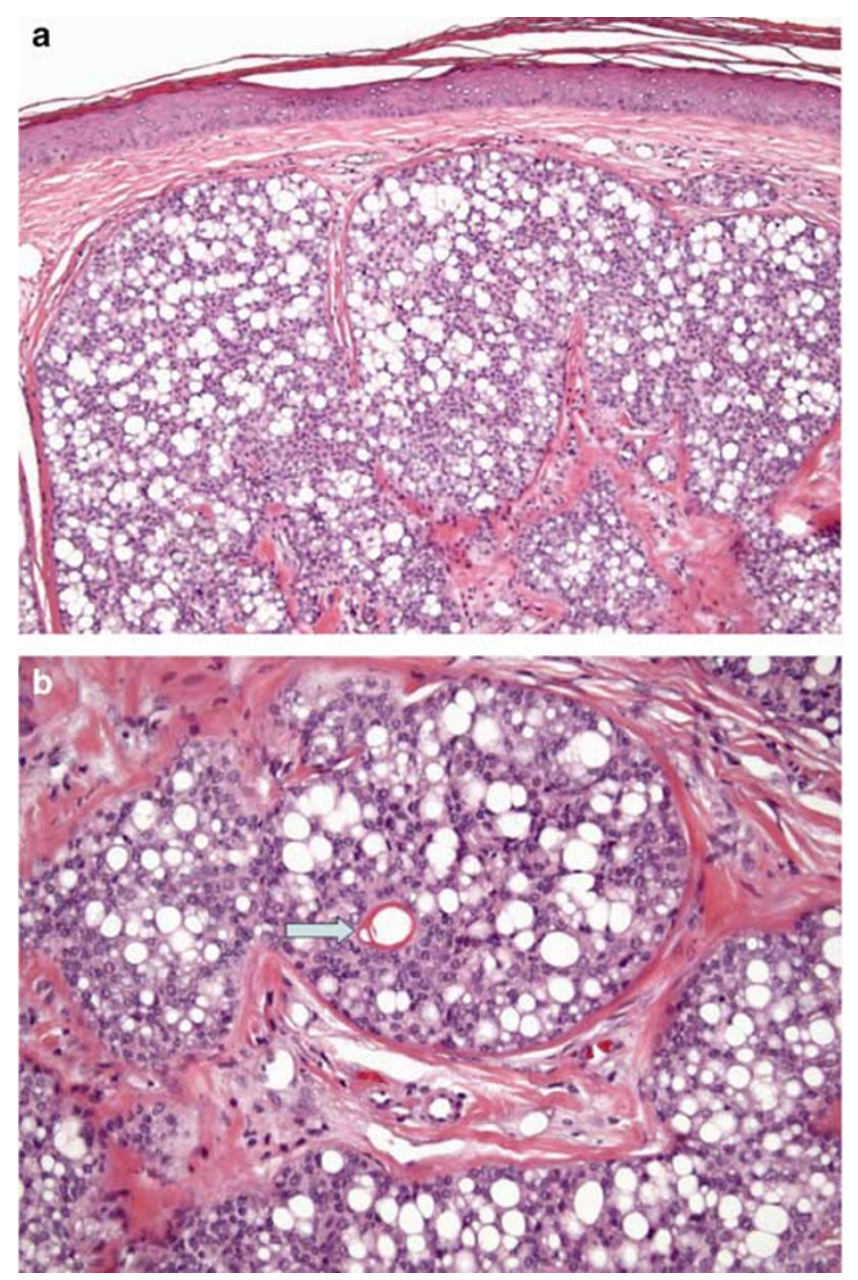

Figure 2 Sebaceoma. Sebaceoma is characterized by a diffuse admixture of germinative epithelia and sebocytes with no compartmentalized, organized pattern as seen in sebaceous hyperplasia and sebaceous adenoma (a). Intimately admixed with these lobules of haphazardly arranged germinative cells and sebocytes are pilosebaceous ducts (b, straight arrow). These manifest an eosinophilic lining cuticle in which keratohyalin granules are characteristically absent.

and typically lack an infiltrative pattern of growth with a sclerosing stromal reaction. The sebaceous component in the center of the tumor lobules decorates with antibodies to the epithelial membrane antigen (EMA). ${ }^{27}$

\section{Sebaceous carcinoma}

\section{Introduction}

In theory, sebaceous carcinoma can occur anywhere where sebaceous glands are located. In practice, ocular sebaceous carcinoma is far more common than its extraocular counterpart, although both are aggressive and potentially lethal malignant neoplasms. ${ }^{3-5,28-39}$ 


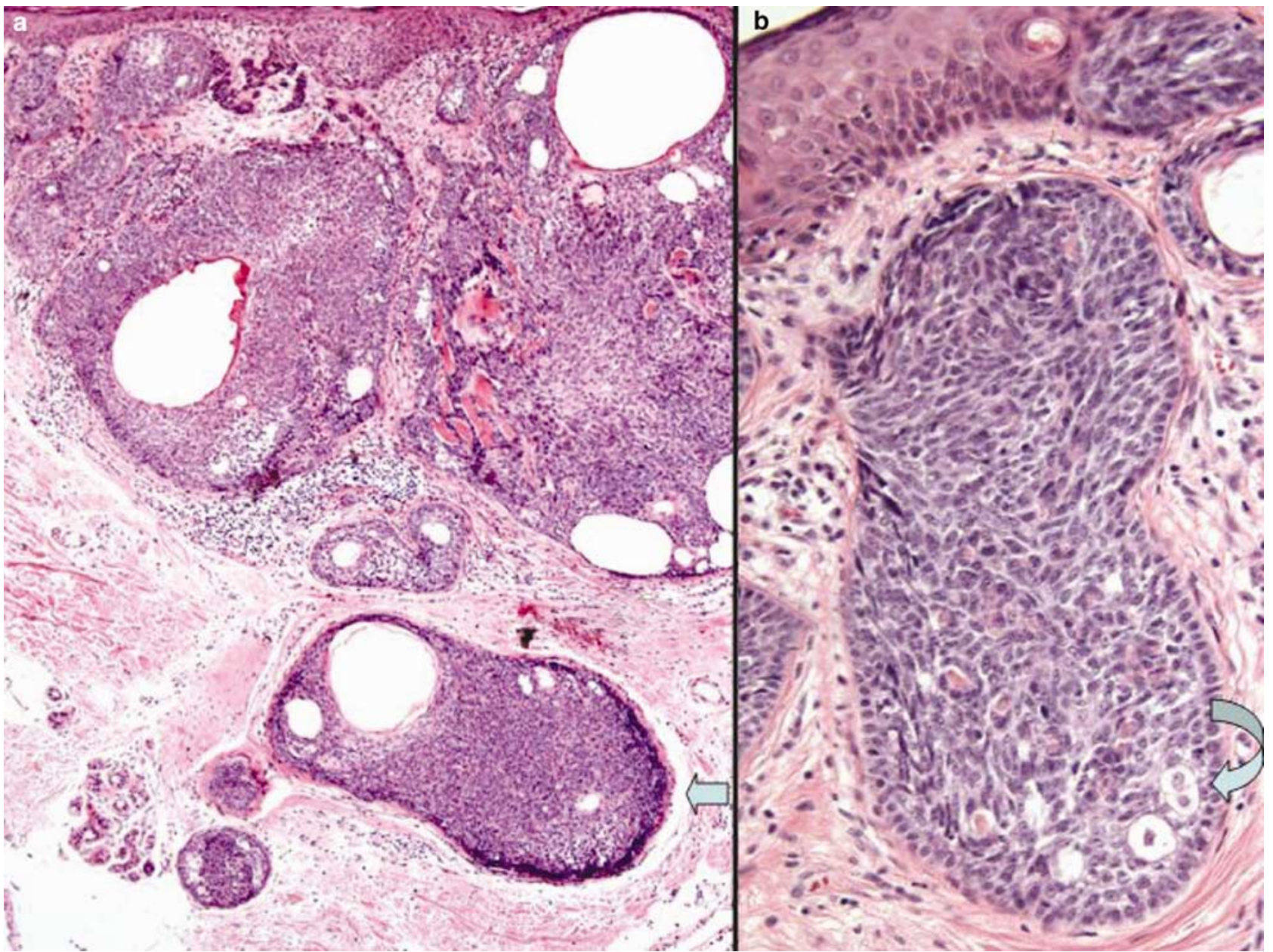

Figure 3 Sebaceous epithelioma. The sebaceous epithelioma is equated by many observers with the BCC/epithelioma with sebaceous differentiation. The tumor comprises nodules dominated by germinative epithelia (a) in which slit-like stromal retraction is seen (a, straight arrow). In many instances, the sebocytes are difficult to identify (b, curved arrow). Unlike the sebaceous adenoma, the germinative epithelia in a sebaceous epithelioma comprise greater than $50 \%$ of the population in any given tumor lobule. Like other forms of BCC, apoptosis and mitotic activity is frequently seen within tumor lobules.

\section{Clinical Features}

Sebaceous carcinoma is a disorder of middle-aged to elderly individuals with a mean age of $62-72$ years and a female preponderance. ${ }^{28-40}$ Although ocular sebaceous carcinoma is said to have a predilection for Asians, this has not been our experience; this may reflect selection bias based upon our practice profiles, however. Patients classically develop painless nodules or papules along the eyelid margin or in palpebral conjunctiva. The upper eyelid is preferentially involved, followed by the lower lid, the caruncle and the bulbar conjunctiva. ${ }^{40}$ In most cases these are solitary, but on occasion a patient develops a multicentric lesion. With respect to the solitary tumors, a chalazion is a frequent initial clinical diagnosis. With respect to the multicentric tumors, misdiagnosis as ocular pemphigoid, actinic keratosis, basal or squamous epithelial neoplasia is common. ${ }^{30}$ Other locations, including elsewhere in the head and neck, the trunk, genitalia and extremities may be seen. ${ }^{28,30,33-35,37,41}$ The extraocular tumors may exhibit equally aggressive biologic behavior to their ocular counterparts. ${ }^{42}$ They are frequently larger, manifesting as nodular tender or nontender, slowly or rapidly growing masses, which in some cases ulcerate. The presence of a sebaceous carcinoma is, in some patients, a clue to internal organ malignancy in the setting of Muir-Torre syndrome. ${ }^{13}$ Some $30 \%$ of patients with Muir-Torre syndrome manifest sebaceous carcinoma. ${ }^{43,44}$

\section{Histopathology}

Depending upon the degree of differentiation, the identification of sebaceous differentiation can be problematic. In low-grade tumors, multi-vesicular cytoplasms indent the nucleus in a fashion similar to the banal sebaceous epithelium of the sebaceous adenoma. Such tumors tend to form confluent nodular masses associated with little or no stromal 
desmoplasia, scattered mitoses and mild nuclear pleomorphism with nucleolation (Figures 4 and 5). High-grade tumors show scant cytoplasmic vacuolation with more prominent nucleoli, atypical mitoses and abundant necrosis (Figures 6-8). These are the tumors more likely to show pagetoid spread, although low-grade neoplasms may also do this; infiltrative patterns of growth with stromal desmoplasia and invasion of adjacent structures are features seen almost exclusively in the high-grade neoplasms (Figure 6).

With respect to grading, architectural patterns rather than cytologic features are more reproducible. $^{29}$ Tumors comprising rather monomorphic rounded nodules of similar size and shape lacking a desmoplastic stroma are usually graded as I/III. Those with variably sized tumor lobules, including those with jagged edges, an indistinct peripheral margin, an infiltrative pattern of growth and stromal desmoplasia and/or a percolating growth pattern through stroma, are

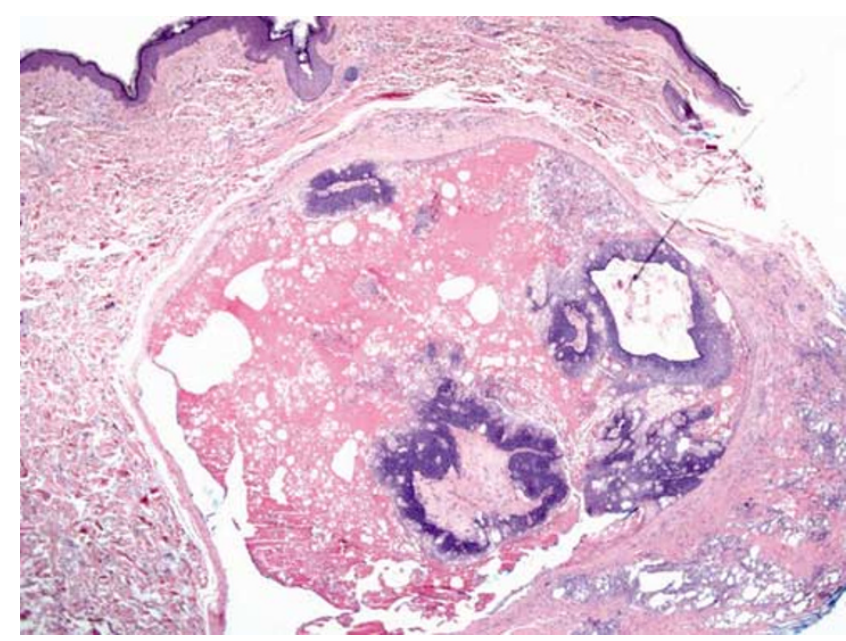

Figure 4 Sebaceous carcinoma, low grade. The tumor illustrated is that of a 39-year-old man with a 1.8-cm diameter lesion on his right arm. A well-circumscribed nodule with a pushing contour shows the presence of atypical germinative epithelia with only scattered sebocytes and areas of necrosis.

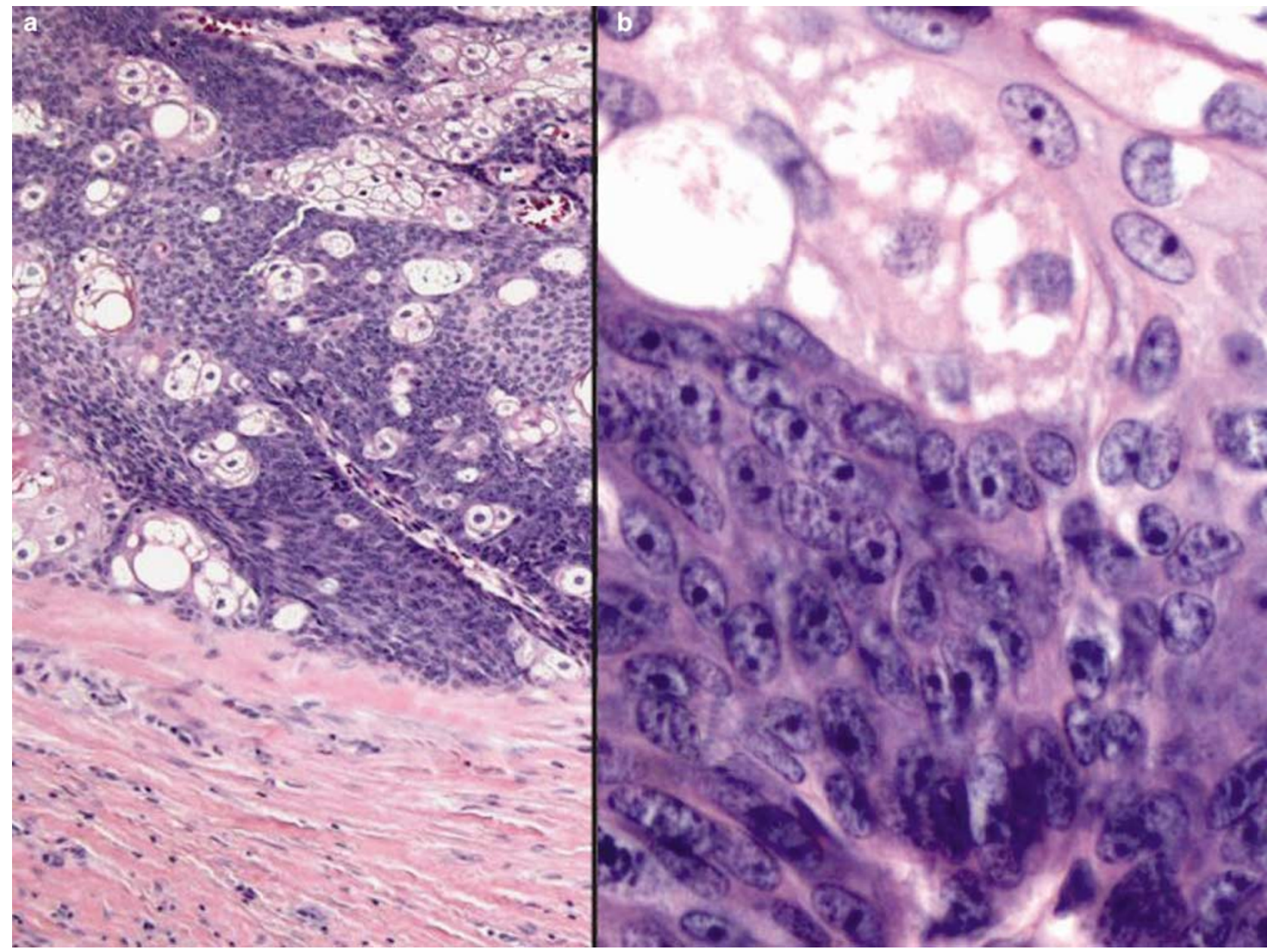

Figure 5 Sebaceous carcinoma, low grade. Higher power microscopy of the same lesion illustrated in Figure 4 shows a dominant component of germinative epithelia within tumor lobules (a) that do not show slit-like retraction of stroma, and are thus dissimilar from the tumor nests in a sebaceous epithelioma. At high-power microscopy (b), the germinative epithelia are shown to have cytologic features of malignant neoplasia by virtue of irregularly thickened chromatinic rims and coarse, spiculated chromatin patterns. 
graded as III/III. The grade II/III neoplasms show an intermediate architectural pattern with both rounded and infiltrative or jagged tumor nests.

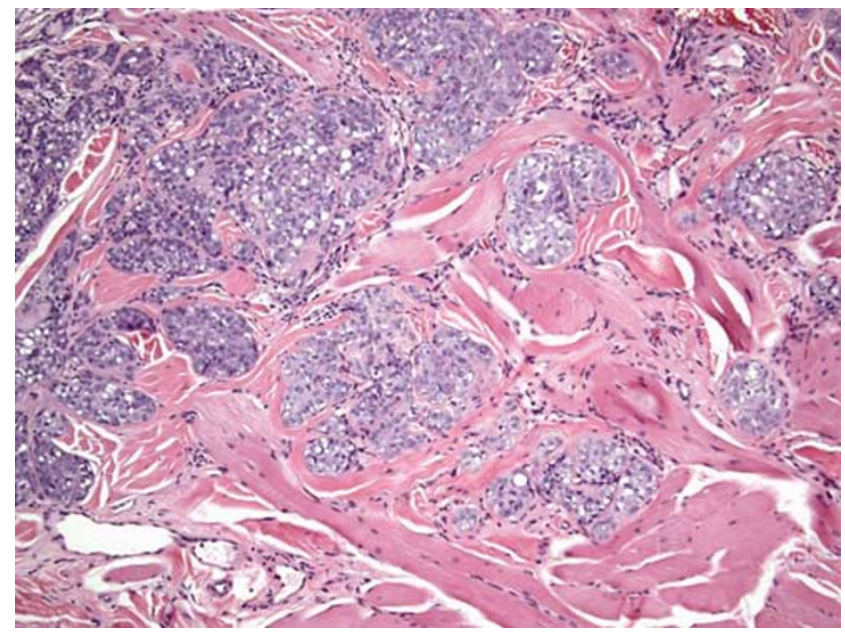

Figure 6 Sebaceous carcinoma, high grade. In this tumor from the nose of a 78-year-old man, neoplastic sebocytes show an infiltrative pattern of growth into the skeletal muscle.
Sheet-like or syncytial growth patterns point towards grade III tumors when seen.

As mentioned above, high-grade tumors infiltrate more aggressively, but all sebaceous carcinomas can show a pagetoid pattern of spread in the overlying epidermis. Careful attention to morphology and to immunohistochemical findings and conventional histochemistry should enable distinction (see differential diagnosis). In practical terms, when confronted with an eyelid biopsy showing a clear cell neoplasm, particularly when pagetoid epidermal involvement is identified, one must always think of sebaceous carcinoma and perform the appropriate investigative studies to include or exclude this diagnostic consideration. The Ki-67 labeling index was much higher than that of squamous cell carcinoma in one study. ${ }^{45}$

Other histologic features of sebaceous carcinoma can obscure the diagnosis. In particular, those lesions showing squamous differentiation with keratin pearls, intercellular bridge formation and cytoplasmic keratinization may strongly mimic a poorly differentiated or moderately differentiated

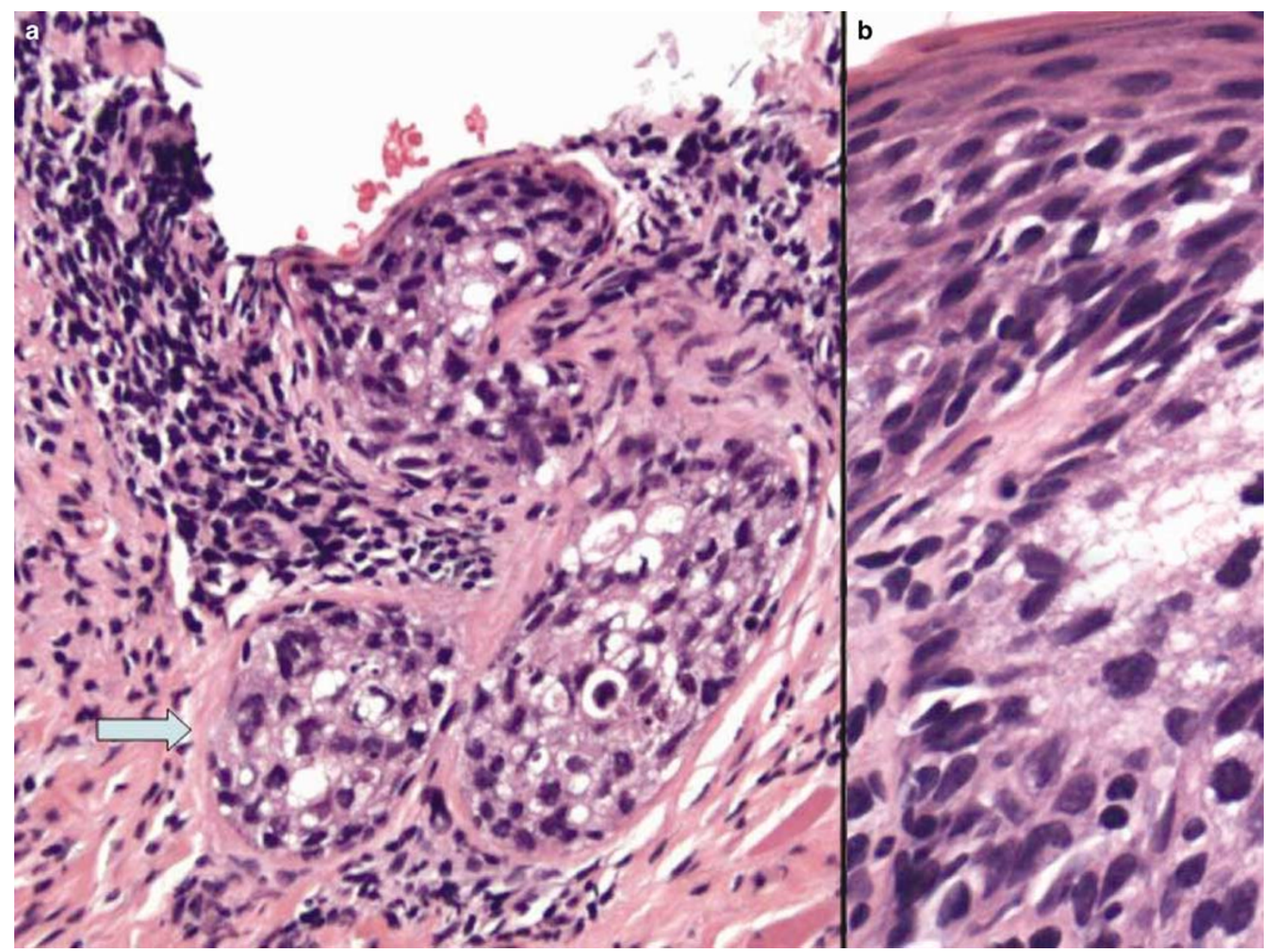

Figure 7 Sebaceous carcinoma, high grade. In addition to pagetoid spread through the epidermis of this elderly man's eyelid, the neoplastic sebocytes are shown to occupy the subepithelial sebaceous adnexal glands (a, straight arrow). (b) Fully transformed malignant nuclear change in sebocytes, which show only minor and inconspicuous cytoplasmic vacuolation. 


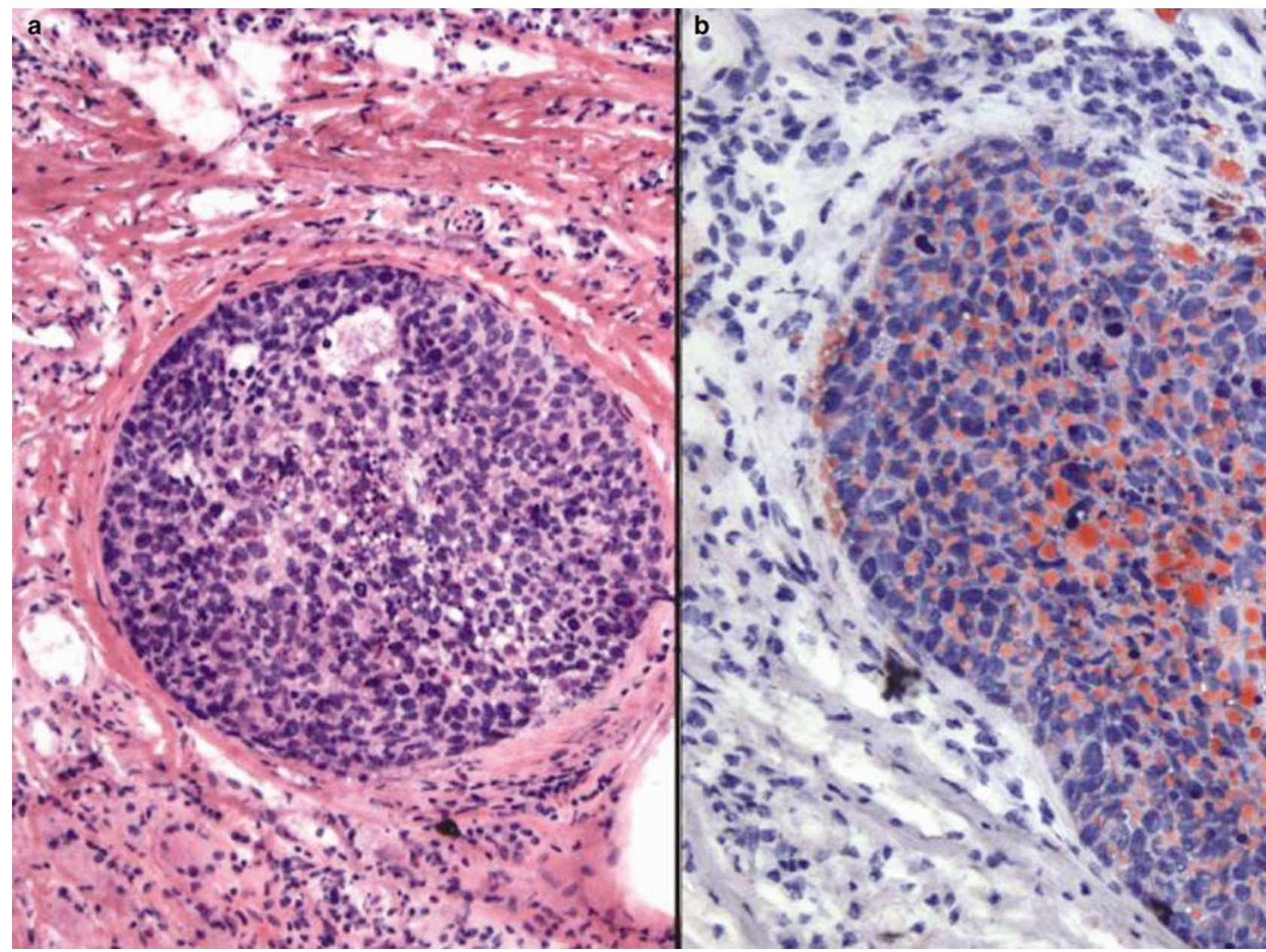

Figure 8 Sebaceous carcinoma. Additional illustrations from the same lesion shown in Figure 7 were obtained at the time of frozen section. Neoplastic colonization of the subepithelial ocular adnexae is identified (a). The definitive test for sebaceous differentiation is an oil red $\mathrm{O}$ histochemical preparation in frozen section material. The neutral lipid decorates with a bright red tinctorial quality (b).

squamous cell carcinoma; areas of sebaceous differentiation may not be readily apparent in such tumors. There is also a sarcomatoid or spindle cell variant which mimics a spindle cell squamous cell carcinoma. ${ }^{46,47}$ A basaloid form comprising small cells having scant cytoplasm and showing peripheral palisading can mimic a BCC. ${ }^{3,28-30,48}$ Apocrine differentiation is rarely described in sebaceous carcinoma. ${ }^{49}$ Some sebaceous carcinomas manifest a trabecular or rosette-like architecture mimicking neuroendocrine neoplasia. ${ }^{50}$ Cystic change in sebaceous neoplasms is said to be specific for Muir-Torre syndrome, where sebaceous neoplasms often prove otherwise difficult to classify precisely. ${ }^{51}$ Associated with sebaceous neoplasms in this setting are keratoacanthomas showing sebaceous differentiation; these are seen in $20 \%$ of Muir-Torres cases and are said to be specific to the syndrome. ${ }^{51}$

\section{Differential Diagnosis}

One challenging differential diagnosis is that of the clear cell epithelial neoplasms, in particular, clear cell squamous cell carcinoma and clear cell BCC. With respect to the clear cell basal and squamous cell carcinomas, the cytoplasmic vacuolation is due to glycogen; therefore, a PAS stain with and without diastase will demonstrate the abundant globules of PAS-positive material. In sebaceous carcinoma, glycogen is typically less abundant, but will be seen. Immunohistochemically, sebaceous carcinomas decorate strongly with EMA. In contrast, squamous cell carcinomas decorate weakly and BCCs are negative with this marker. Furthermore, sebaceous carcinomas decorate strongly with low-molecular-rate cytokeratins (CKs) (ie CAM 5.2), which only decorate the peripheral basaloid rim of a BCC and which are not expressed by squamous cell carcinoma. ${ }^{52}$ Extraocular sebaceous carcinomas tend to decorate with antibody CU18, which recognizes the antibreast carcinoma-associated antigen-225, anti-CA15.3 antibody and anti-CD15 antibody. ${ }^{53}$ Other novel markers such as the Thompson-Friedenreich antigen, said to be expressed in sebaceous neoplasms of both benign and malignant type but not in squamous and basal cell tumors, ${ }^{54}$ have yet to be vetted by multicenter 
studies. The biologic basis of the visceral and sebaceous neoplasms in Muir-Torre syndrome is an aberrant mismatch repair gene (MSH2); this can be assayed immunohistochemically and is absent in the sebaceous neoplasms in this setting. ${ }^{55}$ If one is fortunate enough to have frozen sectioned material, an oil red $\mathrm{O}$ stain will demonstrate the neutral lipids present in the sebaceous carcinomas, which are absent in clear cell squamous cell and BCCs. Typically less challenging diagnostically is Paget's disease. In Paget's disease, the neoplastic cells, typically of apocrine sweat gland derivation, manifest intracytoplasmic vacuoles containing epithelial mucin demonstrable with mucicarmine or Alcian blue-PAS preparations. In Paget's disease, the cells also express carcinoembryonic antigen (CEA) and may express S100 protein, gross cystic disease fluid protein (GCDFP-15), CD15 and, in institutions which have access to these immunohistochemical markers, CA125, CA19-9, ${ }^{56}$ CU18, CA15.3 and B6.2..$^{53}$

Other clear cell neoplasms that can mimic sebaceous carcinoma include balloon cell melanoma, clear cell eccrine carcinoma and metastatic clear cell carcinomas of kidney and thyroid gland. The balloon cell melanoma shows melanocyte lineagespecific markers that are expressed dominantly in the non-balloon cell areas of the tumor. Thus, the epithelioid or sheet-like growth patterns will demonstrate Melan-A and HMB-45 positivity, as well as Mit-f immunoreactivity. Melanin granules should be demonstrable in tumor cell cytoplasms, but may require assiduous and time-consuming high-power microscopic examination. Clear cell eccrine carcinomas, like the clear cell squamous cell and BCCs, are glycogen rich; they strongly express low-molecular-weight CKs and will be strongly EMA positive; thus, in this particular differential diagnosis, the presence of cytoplasmic glycogen in the absence of the T-antigen is an important diagnostic clue. Clear cell carcinoma of the thyroid gland expresses thyroid transcription factor (TTF), as will metastatic clear cell carcinoma of the lung, and in both cases the cytoplasmic vacuolation is due to glycogen accumulation. Similarly, clear cell renal cell carcinoma is a glycogen-rich tumor which, like the clear cell carcinoma of the thyroid gland, has a highly vascular stroma, as would be uncharacteristic of a sebaceous carcinoma. Finally, the clear cell atypical fibroxanthoma merits consideration in the differential diagnosis of sebaceous carcinoma; the former expresses CD68 and other histiocyte lineage markers and often coexpresses EMA in the spindle cell population. ${ }^{57,58}$ The use of procollagen I has been advocated by some authors, but there is significant overlap with spindle cell melanoma and spindle cell squamous carcinoma. ${ }^{59}$

Distinction of sebaceous adenoma and sebaceous epithelioma from sebaceous carcinoma morphologically is discussed above. The expression of p21 in sebaceous adenoma and sebaceoma is said to have a distribution similar to that of the normal sebaceous gland, being dispersed towards the peripheral, germinative areas of the sebaceous lobule, whereas in sebaceous carcinoma, there is a loss of this topogaphical locatization of p21 expression. ${ }^{60}$

The squamoid variant of sebaceous carcinoma expresses the glycoprotein BER-EP4 immunohistochemically, which squamous cell carcinoma does not, ${ }^{61}$ and also has, at least focally, multivesiculated sebocytes that are absent in conventional squamous cell carcinoma. The basaloid variant of sebaceous carcinoma is a form of poorly differentiated sebaceous carcinoma with highly atypical nuclei larger than the prototypic BCC; these tumors lack the mesenchymal mucin deposition around basaloid tumor nests, which one associates with BCC. Sebocytes are rare in the basaloid sebaceous carcinoma, whereas they are abundant in BCC with sebaceous differentiation and absent in conventional BCC. With respect to the differential diagnosis from sebaceous epithelioma, EMA expression is only seen in the sebaceous areas and is absent in the germinitive cells, which constitute $>50 \%$ of the diameter of a typical tumor nodule. Both basaloid sebaceous carcinoma and BCC with sebaceous differentiation express BER-EP4.

\section{Nevus sebaceus}

\section{Introduction and Clinical Features}

The nevus sebaceus may present at birth or in young life, but, in practical terms, patients may be unaware of these lesions until their adulthood. Thus, even patients in the fourth to sixth decades of life occasionally have a lesion biopsied to exclude a carcinoma or keratosis, which is in fact a nevus sebaceus. Typically located on the scalp, a nevus sebaceus may produce a localized area of alopecia or manifest as a tan-colored plaque with a rough surface, the latter representing the epidermal component. Prior to puberty, these lesions have no significant sebaceous component, thus the tan or a brown coloration. In and around puberty, sebaceous glands become prominent and the coloration of the plaque changes from tan-brown to yellowish and the contribution of the sebaceous component produces a verruciform surface. Rare cases are associated with systemic abnormalities such as seizures, mental retardation or defects in visual fields. ${ }^{62-67}$

\section{Histopathology}

The nevus sebaceus comprises a hamartoma with contributions from epidermal and adnexal structures and mesenchymal elements, the varying proportions of which depend upon whether the patient is pre- or post-pubertal. Prior to puberty, the 
nevus sebaceus may have no identifiable sebaceous elements and is recognizable therefore by the presence of a verruciform epidermal hyperplasia with prominence of adnexal structures including in the context of ectopic apocrine glands. Near or after puberty, sebaceous glands become prominent. These are abortive miniaturized sebaceous glands that do not connect in the normal fashion through the sebaceous duct to the necks of the follicular bulges, but instead open directly to the epidermal surface. The lack of association with a mature pilosebaceous unit is associated in turn with a lack of polarizable terminal or vellus hairs. Thus, as mentioned above, we often use polarized light microscopy to delineate the transverse edge of the lesion; where mature hair shafts are identified, the histomorphology represents normal pilosebaceous structures of the native scalp. Like the sebaceous glands, the apocrine component is typically not conspicuous prior to puberty. A variety of additional lesions may be seen in the setting of a nevus sebaceus, ${ }^{68}$ which are, at least at inception, possibly hamartomatous in character. These include basal cell epithelioma, proliferating pilar tumor, syringocystadenoma papilliferum, trichilemmoma, apocrine adenoma, sebaceous adenoma, piloleiomyoma and desmoplastic trichilemmoma. ${ }^{69}$ Although these proliferations may initially be hamartomata, ${ }^{70}$ there is no question that neoplastic transformation can occur. In a fashion cognate to that described in the transformation of superficial and nodular to infiltrative growth BCC, ${ }^{71}$ the elaboration of cytokines by T-helper lymphocytes may immortalize basaloid epithelia. Subsequent mutagenic 'hits' might then lead to an aggressive BCC. Other undisputed malignant neoplasms shown in continuity with the nevi sebaceus include squamous cell carcinoma and ductal apocrine adenocarcinoma. ${ }^{72,73}$

\section{Differential Diagnosis}

The nevus sebaceus is distinguished from sebaceous hyperplasia by the character of the sebaceous lobules (ie being miniaturized with an abortive character and opening to the epidermal surface as opposed to the pilosebaceous apparatus); nevus sebaceus lacks the prominence of germinitive epithelium seen in BCC with sebaceous differentiation. Other forms of papillary epidermal hyperplasia, which can mimic those of the nevus sebaceus, include the epidermal nevus, other hamartomas such as Becker's nevus, and even old verrucae and seborrheic keratoses. Of course, verrucae and seborrheic keratoses lack the other constituents of the multilineal hamartoma, which nevus sebaceus represents. Becker's nevus lacks the prominence of sebaceous glands, but is also a hamartoma and may show increased numbers of hair follicles and/or smooth muscle bundles.

\section{Malignant neoplasms of the folliculosebaceous apparatus}

Malignant tumors arising in the pilosebaceous unit are rare and are often difficult to classify as they may show divergent differentiation patterns defying precise identification.

\section{Trichilemmal carcinoma}

\section{Clinical Features}

The trichilemmal carcinoma arises in hair-bearing, sun-damaged skin typically involving the face, scalp or ears. ${ }^{74-82}$ Either sex can be affected. The lesion present as a nodular plaque typically $<3 \mathrm{~cm}$ in diameter, which may have a pale or reddish discoloration, or as an exophytic or polypoid nodule. ${ }^{83}$ Thus, the lesion is mistaken clinically for basal cell or squamous cell carcinoma or, because of its rapid growth, keratocanthoma. Unlike trichilemmoma, the trichilemmal carcinoma is not associated with Cowden's syndrome. Lesions have been said to be somewhat more indolent than conventional squamous cell carcinoma, but aggressive local growth, recurrence and metastasis are well-recognized risks. ${ }^{84}$

\section{Histopathology}

The true trichilemmal carcinoma replaces the epithelium of one or more hair follicle structures generating a lobular pattern of growth and mimicking, in the affected root sheath epithelium, Bowen's disease. An infiltrative pattern of growth with stromal desmoplasia and tongues of tumor radiating from the affected follicular structures is noted (Figure 9). Angioinvasion or perineural infiltration may be seen. Foci of clear cell change due to the presence of cytoplasmic glycogen are an important clue to diagnosis. In some cases, the lobules of trichilemmal carcinoma manifest peripheral palisading cognate to a trichilemmoma, but the highgrade nuclear atypia, mitoses and individual cell necrosis enable distinction. There may be pagetoid spread of the interfollicular epidermis and of the affected follicular structures.

\section{Differential Diagnosis}

Conventional squamous cell carcinoma arising in the interfollicular epidermis, but showing clear cell differentiation, clear cell BCC, certain types of eccrine carcinoma, balloon cell melanoma, sebaceous carcinoma and metastatic clear cell adenocarcinomas of lung, ovary, kidney and thyroid gland all merit consideration. The diagnostic features of these differential diagnoses have been previously considered and will not be reiterated. It is noteworthy that antibodies to certain keratins selective for the 
S102

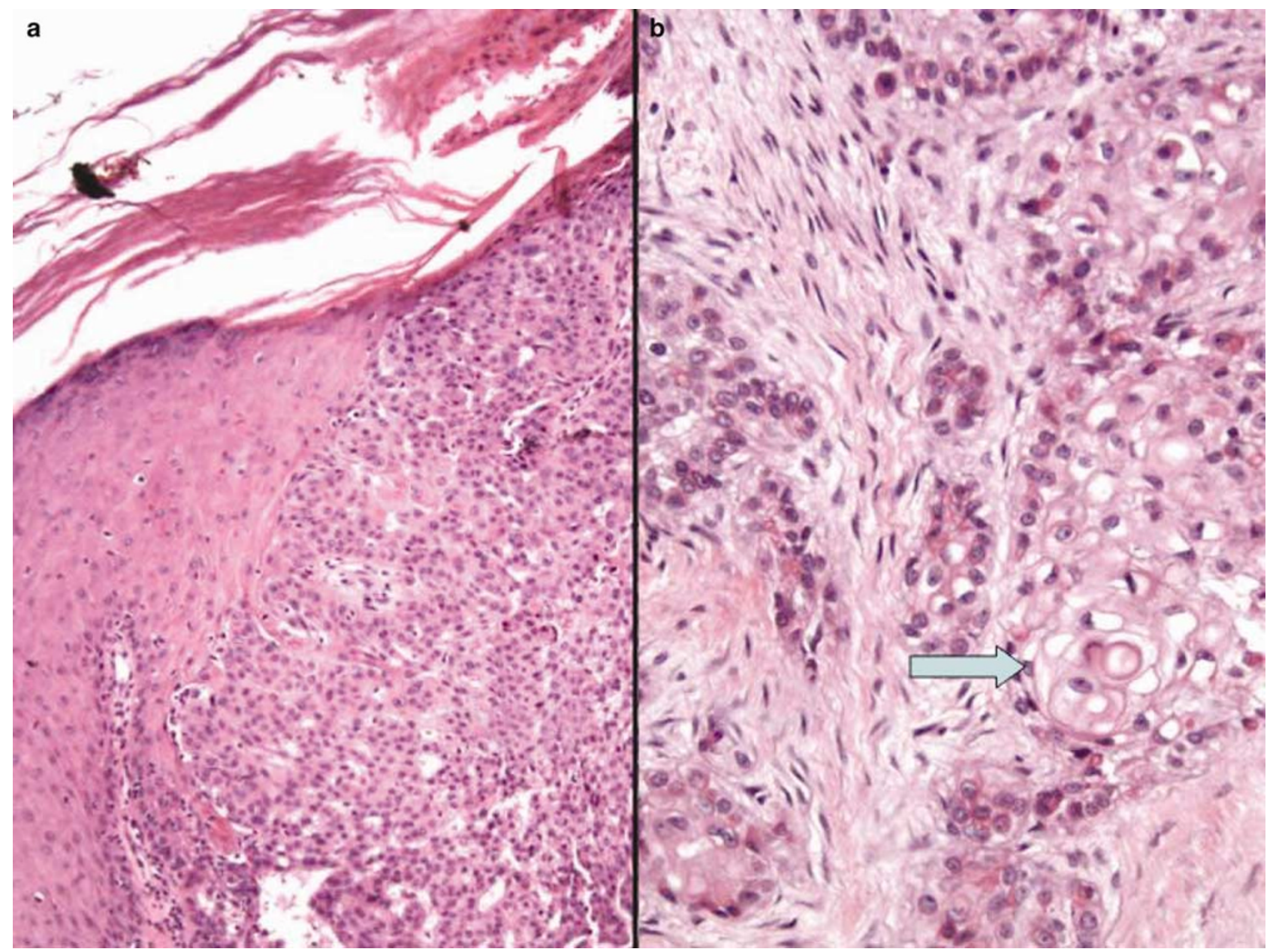

Figure 9 Tricholemmal carcinoma. Tumor tongues radiate from follicular epithelia and from the intrafollicular epidermis (a), showing an infiltrative pattern of growth with reactive stromal desmoplasia, angioinvasion, perineural infiltration and pagetoid spread through the intrafollicular epidermis. Note the abundant clear cell change in tumor lobules (b, straight arrow); this is due to the accumulation of intracytoplasmic glycogen as characterizes tumors of follicular outer root sheath derivation.

follicular epithelium, such as AE13 and AE14, may be of assistance. One case report described CK 17 and c-erb-B2 expression in a trichilemmal carcinoma, a pattern purported to confirm the outer root sheath derivation of this neoplasm. ${ }^{85}$ The 'hair differentiation' keratins are said to include CK 7, 8 , 18 and 19; CD34 expression is also a feature said to support outer root sheath differentiation. ${ }^{86,87}$

\section{Malignant proliferating pilar tumor}

\section{Introduction and Clinical Features}

The rare malignant proliferating pilar tumor may arise in the background of a pre-existing pilar tumor or proliferating tricholemmal cyst. The distinction is a histopathologic one.

\section{Histopathology}

The malignant proliferating pilar tumor can be low or high grade in character, and in either manifests infiltration of the dermis and subcutaneous tissue by irregularly shaped and irregularly sized nests of malignant cells in high-grade neoplasms and of proplastic atypical cells in low-grade neoplasms. The high-grade malignant proliferating pilar tumor lacks a lobular pattern and instead grows as individual cell cords or irregular nests with jagged contours associated with striking stromal desmoplasia, numerous and atypical mitotic figures, and in some foci a neoplastic spindle cell morphology. ${ }^{88,89}$

\section{Differential Diagnosis}

Early on in its development, the pilomatricoma can show brisk mitotic activity and has cells which are proplastic with large oval nuclei and prominent nucleoli. These features may be worrisome for malignancy, but in fact the tumors are well circumscribed, lacking invasion of adjacent structures and necrosis. In addition to the admixed areas of germinitive and shadow cells, the pilomatricoma is associated with calcified deposits in the adjacent 
stroma with a foreign body giant cell reaction. Residual shadow cell sheets undergo dystrophic calcification, which gives the lesion its alternate appellation. Over time, these lesions lose their brisk mitotic activity and undergo progressive calcification. Ultimately, the lesion eventuates as a so-called 'ancient' pilomatricoma with a florid foreign body reaction and abundant calcification in the adjacent stroma. ${ }^{90,91}$ Metaplastic bone formation in these lesions may subsequently ensue. A perforating variant of the pilomatricoma is uncommonly seen, whereby the necrotic material and shadow cells are extruded through the epidermis or through a hair follicle. ${ }^{90,92-97}$

The distinction from squamous cell carcinoma and the ductal eccrine adenocarcinomas, as well as the occasional metastatic carcinoma with squamous differentiation, is problematic. The malignant proliferating pilar tumor does not connect to the overlying epidermis, shows no glandular differentiation and is held to manifest, like the malignant trichilemmoma, a keratin immunostaining profile similar to the follicular outer root sheath. One case report described the expression of CK 7 and CD34 in a carcinoma arising in a proliferating tichilemmal cyst. $^{87}$

\section{Pilomatrix carcinoma}

\section{Clinical Features}

Classically appearing as a dome-shaped nodule in the head and neck of children and infants, the pilomatricoma is also referred to as the calcifying epithelioma of Malherbe. ${ }^{90,91,98-101}$ It is the prototypic lesion that produces matrical differentiation comprising shadow cells that in turn derive from a germinitive epithelial layer. Its rare malignant counterpart is the pilomatrix carcinoma, a lesion with an aggressive tendency for local recurrence but little metastatic potential. ${ }^{102}$

\section{Histopathology}

A pilomatricoma can be mitotically active in its early phase. In contrast, pilomatrix carcinoma shows broad geographic necrosis with an infiltrative margin and cytological alterations, including fully transformed malignant change. ${ }^{90,91,103-115}$ Matrical differentiation may only be focal in these lesions. Tumors have the potential to spread to regional lymph nodes and produce fatal disseminated metastatic disease. ${ }^{107,115}$ There is a locally invasive form of aggressive pilomatrixoma that shows local recurrence, but not distant metastasis. The histomorphology constitutes a point on a spectrum from the benign pilomatricoma to its malignant metastasizing counterpart. Malignant pilomatricoma shows invasion of adjacent structures, an infiltrative growth pattern and stromal desmoplasia. Metastatic tumor would of course clinch the diagnosis.

\section{Differential Diagnosis}

The identification of matrical differentiation by virtue of ghost cells is the key step towards identifying the lineage of this neoplasm. There is a form of BCC with matrical differentiation; these are typically otherwise classical nodular BCCs that show central matrical change within tumor cell nests.

\section{Adnexal carcinoma with divergent differentiation}

On occasion, one encounters an anaplastic carcinoma with an infiltrative architecture, fully transformed cytologic criteria for malignancy and areas suggestive of divergent differentiation towards eccrine, apocrine, sebaceous or outer root sheath structures. ${ }^{116-119}$

\section{Pilar neurocristic hamartoma}

\section{Introduction and Clinical Features}

It is unclear whether the pilar neurocristic hamartoma represents a true hamartoma or a neoplastic proliferation of germinitive epithelium often associated with pigment-bearing dendritic cells. ${ }^{120-124}$ The pilar neurocristic hamartoma manifests as a plaque or papule with pigmentation in the skin of the head and neck, and can occur in any age group. We have seen a case arising in a 14-year-old African American on the back of the neck. ${ }^{124}$ On occasion, these lesions give rise to a melanoma. ${ }^{125,126}$

\section{Histopathology}

The pilar neurocristic hamartoma manifests sheets of germinitive cells admixed with pigmented cells, with dendritic processes similar to the critical cell of the blue nevus of the dermal melanocytoses. Ultrastructurally, these can be shown to represent melanocytes, while other cells manifest Schwann cell features. These lesions are folliculocentric, thus the designation pilar neurocristic hamartoma. ${ }^{123}$

\section{Neoplasms of the sweat gland apparatus}

\section{Introduction}

Benign and malignant neoplasms may arise in the apocrine and eccrine sweat glands of humans. With respect to the latter, the acrosyrinx (the sweat duct orifice as it traverses the epidermis), the eccrine straight duct (which manifests a vertical column comprising a central cuboidal ductal cell in a 
peripheral myoepithelial layer as it traverses the dermis to the dermal-subcutaneous interface) and the eccrine secretory coil (a variable admixture of secretory, ductal and myoepithelial cells at the dermal-subcutaneous interface) all can represent the source of eccrine neoplasia. The apocrine sweat ducts enter into the hair follicle apparatus at the level of the follicular bulge. The apocrine apparatus typically manifests central decapitation-type secretion, and a coiled architecture and is typically concentrated in the axilla and groins, that is, the fold areas of the skin. Hamartomatous proliferations may cause apocrine ectopia with concentrations of apocrine ductal cells in, for example, the scalp in nevus sebaceus. As the histologic expression of both eccrine and apocrine neoplasms is extremely wide, and as the tumors can be seen in combination with complex hamartomas and/or can exhibit divergent differentiation, an overwhelming and confusing lexicon of diagnostic appellations has been applied to eccrine and apocrine neoplasia. In this treatise, we will attempt to describe in some detail the bestrecognized diagnostic entities for which specific nomenclature should logically be applied. When in doubt about specific subtyping, however, our practice is to identify such an adnexal neoplasm as, for example, 'benign eccrine appendage neoplasm, not otherwise specified' or in the case of malignant neoplasms as 'malignant eccrine appendage tumors'.

\section{Malignant sweat gland neoplasms}

\section{Introduction}

Malignant tumors of the sweat ducts and the secretory apparatus of sweat glands can be classified, as is the case for benign adnexal neoplasms, as those showing predominantly eccrine or predominantly apocrine differentiation.

\section{Eccrine carcinomas}

Malignant eccrine neoplasms tend to have a morphology that parallels that of malignant tumors of the ductal epithelia of the mammary glands. ${ }^{127}$ In consequence, it is sometimes difficult to exclude metastatic disease when dealing with a primary eccrine carcinoma. In a comparison between primary sweat gland tumors and metastatic breast carcinoma to skin, Busam et al ${ }^{128}$ found that use of antibodies against epidermal growth factor receptor strongly decorated $81 \%$ of sweat gland tumors, but only $17 \%$ of metastatic breast cancers $(P<0.001)$. There was no significant difference between the skin tumors and metastatic breast carcinoma when antibodies against estrogen and progesterone receptors were used. In another study comparing benign and malignant primary eccrine and apocrine neoplasms to metastatic breast carcinoma, only $3.5 \%$ of these primary adnexal cancers demonstrated HER-2 positivity, whereas $10-23 \%$ of the breast carcinomas were positive. ${ }^{129}$ The authors suggested that this test may be useful in distinguishing primary skin cancers from metastatic breast cancers. ${ }^{129}$ Another study showed that primary cutaneous neoplasms stained strongly for p63 and CK 5/6 with high specificity, while CK 7 and 20 were not useful. ${ }^{130}$ When CK 7 was positive in the cutaneous lesions, it exhibited marked focality and a specific pattern, while metastatic breast carcinoma did not express p63 or CK $5 / 6$ as strongly or as often; metastatic breast cancers diffusely expressed CK 7, which was only focally positive in primary adnexal tumors. The usefulness of CK 5/6 was again shown by Plumb et $a l^{131}$ in the differentiation of a cutaneous neoplasm from a metastatic breast carcinoma. Ivan et $a l^{132}$ presented further evidence of the usefulness of p63 in the diagnosis of adnexal cancer; in their study, none of the examples of metastatic adenocarcinoma to skin stained for p63, whereas virtually all the adnexal carcinomas were positive. Another study suggested using Ki-67 and p53 in atypical adnexal tumors to aid in differentiating benign from malignant lesions. These studies introduce the utility of molecular methods in understanding the pathogenesis of sweat gland cancers and in attempting to differentiate them from metastatic carcinoma, especially of the breast, as it affects the skin. In this review, we will emphasize those diagnostic features of lesions that present as primary cancers of the eccrine secretory or ductal apparatus and discuss those features that help to morphologically identify the tumors and to differentiate them from metastatic carcinomas.

\section{Eccrine porocarcinoma}

\section{Clinical Features}

Eccrine porocarcinoma classically presents as a verrucous plaque or nodule of the distal extremities, particularly the lower extremities, the head and neck or trunk of an elderly individual typically in the sixth to ninth decades of life.

\section{Histopathology}

The eccrine porocarcinoma is so designated as it recapitulates the morphology of the eccrine poroma with superimposed features definable as representing a neoplastic process with a potentially aggressive biological character. The latter include an infiltrative pattern of growth accompanied by a desmoplastic stromal reaction, apoptosis of tumor cells, features of high-grade cytologic atypia throughout the neoplasm, nucleolation, hyperchromasia with high nucleocytoplasmic ratios indicating nuclear aneuploidy, perineural invasion, vascular invasion and, in some observers' hands, extensive 
clear cell change in a population showing features of cytologic anaplasia (Figures 10 and 11). ${ }^{133-141}$ Some neoplasms clearly begin in the setting of a preexisting lesion of long duration, suggesting that, for example, eccrine porocarcinoma may arise through malignant transformation of a pre-existing eccrine poroma. The presence of mutant p53 protein in both poroma and porocarcinoma lends molecular support to this hypothesis. ${ }^{142}$ Some observers feel that an invasive pattern of growth in and of itself justifies designation as eccrine porocarcinoma. ${ }^{143}$ The analogy to eccrine poroma extends to an intraepidermal form of porocarcinoma in situ, termed malignant hidroacanthoma simplex, ${ }^{144-147}$ that, like its benign analog, shows sharply demarcated nests of tumor cells within the epidermis, the so-called BorstJadassohn phenomenon. The distinction between malignant and benign hidroacanthoma simplex is based almost exclusively on the identification of cytologically malignant cells within tumor nests. An in situ component of this type may coexist with an

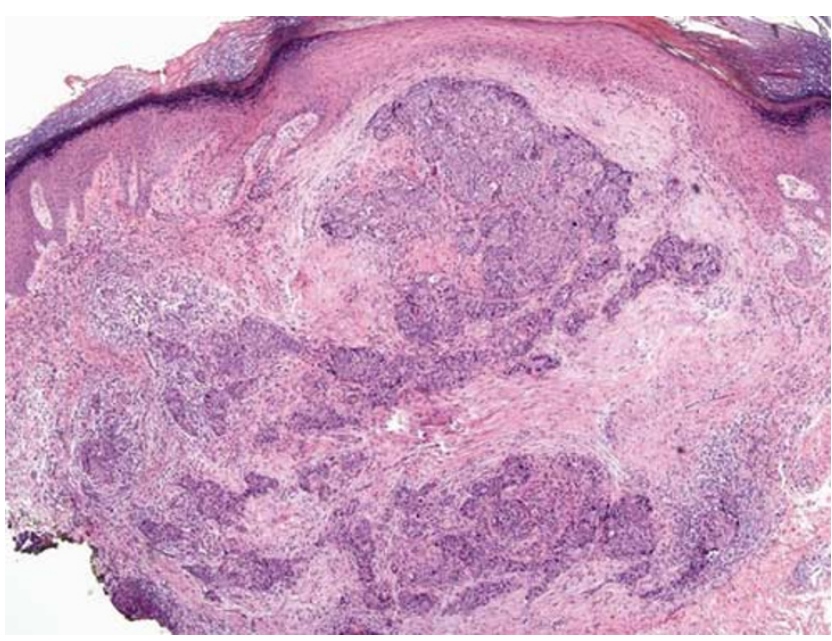

Figure 10 Eccrine porocarcinoma. Eccrine porocarcinoma is characterized by infiltrative cords, lobules and tongues of fully transformed malignant epithelia. The tumor cells have polygonal external contours and show cytoplasmic eosinophilia. There is reactive stromal desmoplasia.

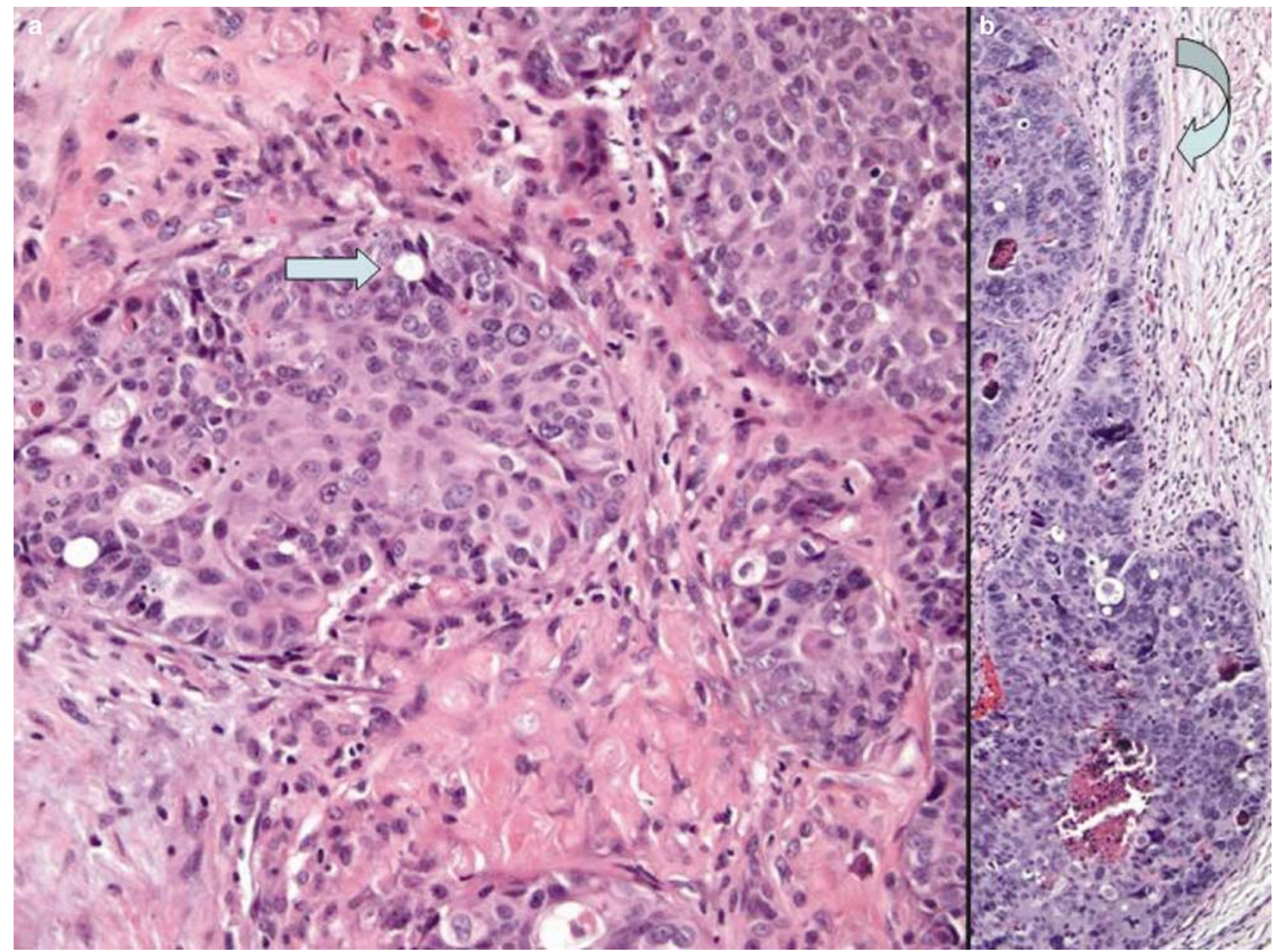

Figure 11 Eccrine porocarcinoma. The same tumor illustrated in Figure 10 shows fully transformed malignant change with intracytoplasmic and common luminal margin formation (a, straight arrow). On occasion, one can see progressive dysplasia with neoplastic transformation of pre-existing eccrine straight ducts (b, curved arrow), a powerful clue to derivation from a pre-existing eccrine structure. In other cases of eccrine porocarcinoma, the tumor tongues and lobules radiate directly from the overlying interfollicular epidermis. 
invasive dermal-based eccrine porocarcinoma and, when present, the former clearly indicates a primary neoplasm. Metastatic tumors mimicking eccrine carcinomas but showing an intraepithelial component are rare. ${ }^{148}$

\section{Differential Diagnosis}

With respect to the purely intraepidermal variant or those tumors showing a significant intraepithelial component, distinction from clonal seborrheic keratosis with atypia, clonal Bowen's disease, melanoma in situ and Paget's disease is essential. The clonal seborrheic keratosis with atypia occurs in sun-damaged skin, with solar elastosis being a prominent feature. Typically, therefore, lesions are on the head and neck area or on the dorsal aspect of the upper extremities. Papillomatosis with pseudohorn cyst formation should make distinction readily apparent at the light microscopic level. If not, both seborrheic keratosis and clonal Bowen's disease fail to express CK 7, CEA or S-100 protein, which is often positive in the porocarcinoma in situ (Figure 12). Melanoma in situ typically expresses $S-100$ protein and will decorate with a Melan-A and/or HMB-45 immunohistochemical preparation; melanoma does not express CEA. The production of melanin by intraepidermal melanocytes and the delivery of melanosomes from the nurse melanocyte to adjacent keratinocytes is a phenomenon which can be reduplicated in neoplastic tumors of eccrine and apocrine derivation. In consequence, melanosomes may be seen in clonal Bowen's disease, Paget's disease and eccrine porocarcinoma in situ. The foregoing can be a cause of confusion, whereby pigmented Bowen's disease, Paget's disease and porocarcinoma in situ can mimic melanoma. The problem is further compounded by the presence of pagetoid migration in Paget's disease or in amelanotic superficial spreading melanoma in situ; this is not, however, a feature that typifies porocarcinoma in situ. ${ }^{149}$ Those tumors with dermal invasion must be distinguished from squamous cell carcinoma and other forms of malignant eccrine neoplasia. The eccrine porocarcinoma, like the eccrine poroma, is

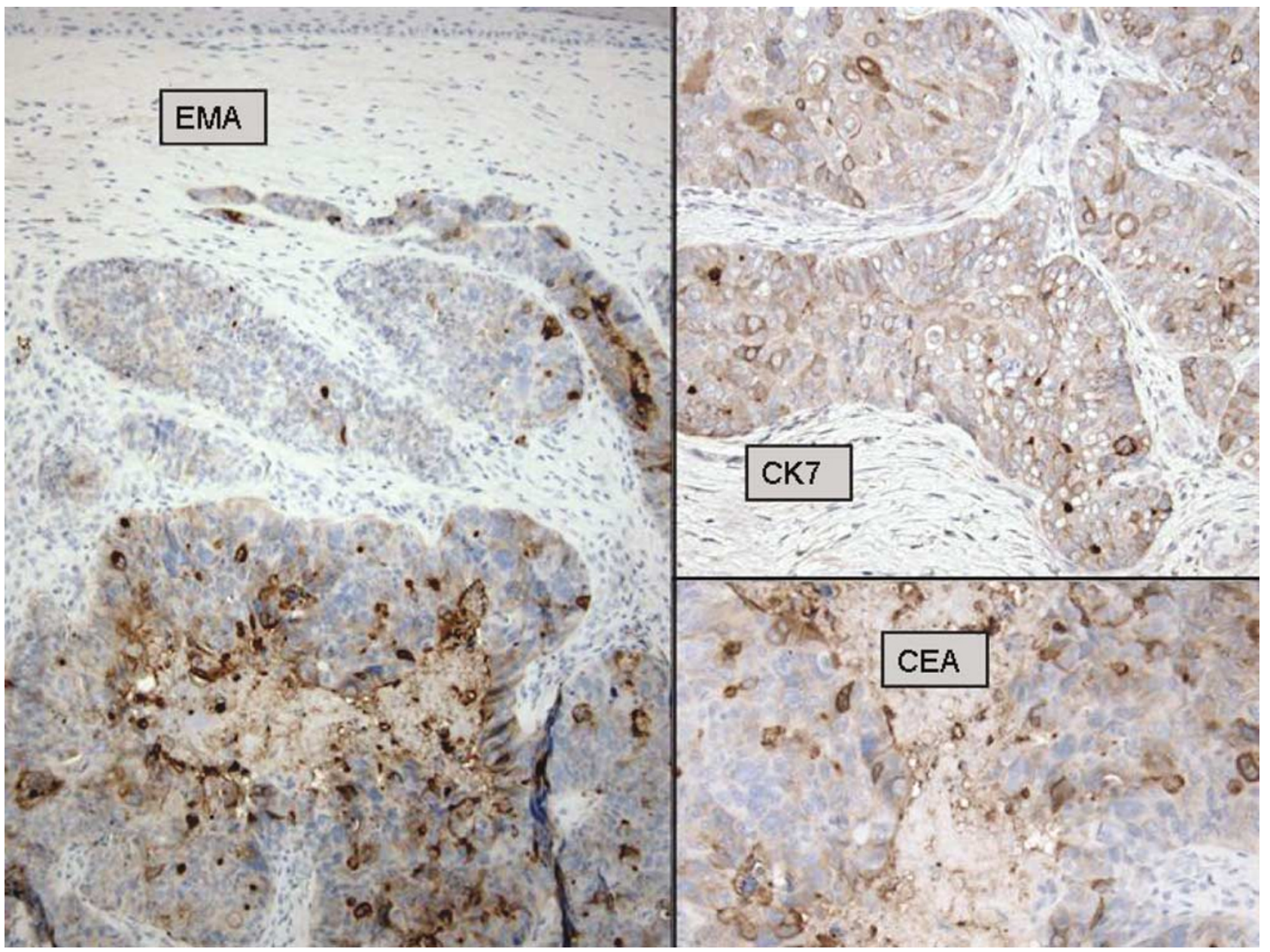

Figure 12 Eccrine porocarcinoma: immunohistochemical profile. The neoplastic lumina in the centers of the tumor lobules frequently decorate with EMA and CEA. The tumors are floridly CK-7 positive, unlike conventional squamous cell carcinoma. 
composed of small cuboidal cells manifesting intercellular bridges and eosinophilic cytoplasms with sharply defined cell borders. The cells and their nuclei are both larger than those seen in the eccrine poroma but are, nonetheless, smaller than the tumor cells of squamous cell carcinoma. Furthermore, porocarcinoma manifests common luminal margin formation and intracytoplasmic lumina. The purely dermal-based eccrine cancers such as microcystic adnexal carcinoma and malignant eccrine acrospiroma have no epidermal component. On occasion, metastatic disease proves impossible to distinguish from primary porocarcinoma with a dermal component.

\section{Hidradenocarcinoma}

\section{Introduction}

A variety of names are applied to dominantly dermal-based malignant eccrine tumors, including hidradenocarcinoma, malignant acrospiroma and clear cell eccrine carcinoma. This is a group associated with aggressive biological behavior and frequent distant metastases.

\section{Clinical Features}

These neoplasms present as nodules, frequently with superimposed ulceration and rapid growth, affecting the head and neck and the distal extremities of the elderly. ${ }^{141,150-154}$

\section{Histopathology}

There is a wide histomorphologic spectrum associated with malignant dermal-based eccrine proliferations. This spectrum includes both architectural and cytological features with overlapping histologies and with more than one cytologic and/or architectural pattern often present in any given neoplasm. In general, the architectural features that characterize these tumors include polypoid neoplasms, tumors with an infiltrative peripheral margin associated with stromal desmoplasia and variants characterized by islands of neoplastic cells showing central necrosis analogous to the comedocarcinoma of the breast. Cytologically, tumors show variable admixtures of basaloid, squamoid and clear cells with foci of common lumenal margin formation and/or intracytoplasmic lumen production, which represent evidence of eccrine ductal differentiation at the light microscopic level. From a cytologic perspective, tumors may be well-differentiated (ie those malignant neoplasms showing an invasive peripheral margin with stromal desmoplasia and/or metastatic deposits in the absence of cytologic anaplasia) to overtly anaplastic cancers with fully transformed nuclear features of malignancy.

\section{Differential Diagnosis}

The hidradenocarcinomas call to mind a variety of differential diagnostic considerations depending upon the architectural and cytologic characteristics of the neoplasm under consideration. With respect to the clear cell hidradenocarcinomas, the differential diagnosis prominently encompasses neoplasms with clear cell differentiation and, in particular, those with malignant nuclear characteristics superimposed upon the aforementioned clear cell cytology. These include clear cell eccrine carcinoma and porocarcinoma, sebaceous carcinoma, trichilemmal carcinoma (which we consider a form of squamous cell carcinoma with clear cell/trichilemmal differentiation), clear cell BCC and clear cell carcinomas metastatic to the skin. With respect to the latter, the dominant diagnostic considerations are metastatic clear cell carcinoma from thyroid gland and lung. The expression of TTF seen in the great majority of these cases is helpful in resolving this dilemma. Some metastatic thyroid cancers also manifest expression of thyroglobulin. Metastatic clear cell carcinoma of renal primary origin manifests a prominent stromal vascularity with hemorrhage and areas of granular necrosis typically evident in biopsy material. Clear cell squamous cell carcinoma of the cervix is a glycogen-rich cancer with intercellular bridge formation characteristic of squamous differentiation. Unfortunately, intercellular bridges are also seen in poromas and porocarcinomas. Correlation with the clinical setting and with diagnostic imaging studies may be necessary to make these distinctions. Sebaceous carcinomas are malignant neoplasm of the sebaceous apparatus, which are most frequent in the eyelids and the head and neck region, but may be seen wherever sebaceous glands are identified. Sebaceous carcinomas manifest colonization of the epidermis and/or the palpebral conjunctiva in a pagetoid array. Outside the ocular adnexae, the lesions manifest an invasive pattern of growth with stromal desmoplasia and infiltration of adjacent structures. If frozen sections are available, an oil red $\mathrm{O}$ preparation will show intracytoplasmic fat globules in sebaceous carcinoma with variable quantities of coarse cytoplasmic glycogen (PAS positive/diastase resistant). Glycogen is more plentiful in clear cell malignant neoplasms of eccrine derivation and also those recapitulating outer root sheath derivation (ie trichilemmal carcinomas/squamous cell carcinomas with trichilemmal or clear cell differentiation). While it is generally accepted that sebaceous carcinoma is an aggressive neoplasm, clear cell BCC manifests local recurrence but typically does not metastasize. Thus, these distinctions are more than semantic in nature and accurate classification is helpful to the clinician whenever possible. The immunohistochemical stains which facilitate this distinction include diffuse strong expression of EMA, low-molecularweight CK (ie CAM 5.2) 52 $^{52}$ and the Thompson- 
Friedenreich (T) antigen ${ }^{54}$ in sebaceous neoplasia, vs peripheral expression of CAM 5.2 in BCC and its complete absence in SCC; EMA is expressed in neither of the two latter neoplasms.

\section{Mucinous eccrine carcinoma}

\section{Introduction and Clinical Features}

The mucinous eccrine carcinoma presents as a pale or violaceous nodule up to $3 \mathrm{~cm}$ in diameter involving the eyelids, face or head and neck of elderly patients. Men and African-Americans are said to be preferentially affected. ${ }^{143}$ This is a tumor with a propensity to local recurrence but, like its analog in the breast, mucinous carcinoma rarely metastasizes to regional lymph nodes.

\section{Histopathology}

The histopathology of mucinous eccrine carcinoma of the skin is analogous to that of its counterpart in the breast, comprising nests of variably cohesive atypical epithelia lying free in pools of mucin. The individual tumor cells manifest hyperchromatic nuclei with nucleolation and a degree of cytologic atypia which varies from low grade to frankly anaplastic (Figures 13 and 14). ${ }^{155-163}$ Cytoplasms are vacuolated and may show signet ring formation with peripheral displacement of the nucleus by a large intracytoplasmic vacuole. Pools of mucin dissect the stroma, creating rounded and irregularly shaped aggregates of PAS-positive, diastase-resistant material which decorates with Alcian blue or with Hale's colloidal iron. ${ }^{158}$ Mitoses are inconspicuous, as is vascular or perineural infiltration. As in the breast, colloid carcinoma of the skin may show neuroendocrine differentiation immunohistochemi-

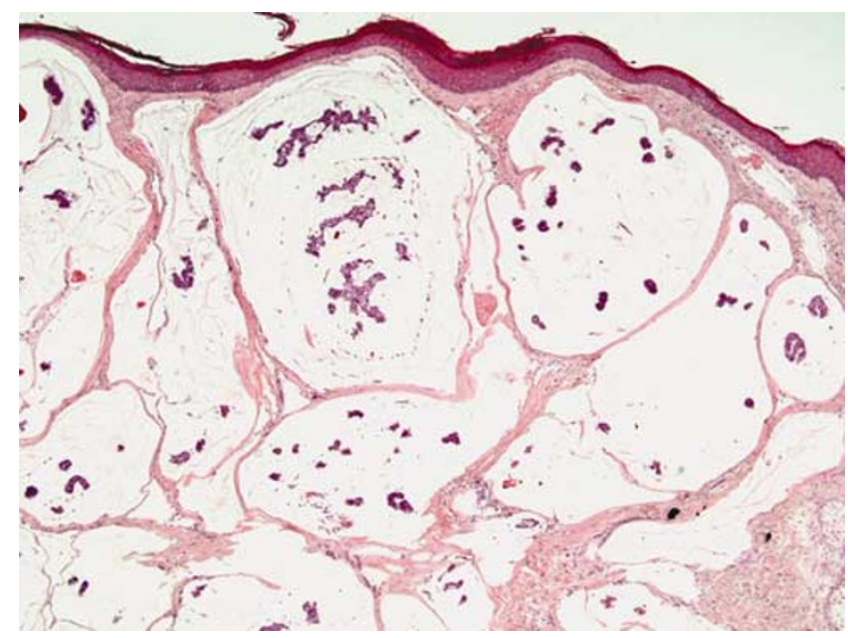

Figure 13 Mucinous eccrine carcinoma. The tumor is characterized by nests of neoplastic epithelia floating in pools of mucin. cally by virtue of synaptophysin and/or chromogranin expression. ${ }^{164}$ In a study of cutaneous tumors employing G-81, a monoclonal antibody reactive to dermcidin, it was suggested that eccrine carcinoma and other eccrine appendage including mixed tumors may at times have both eccrine and apocrine differentiation. ${ }^{165}$

\section{Differential Diagnosis}

Metastatic deposits from colloid carcinomas of the breast or gastrointestinal tract have an identical histomorphology. However, metastases from breast or gastrointestinal tract carcinomas occur late in the disease process and, by this time, the clinical history and biological character of the neoplasm are almost always established. ${ }^{166}$

\section{Adenoid cystic carcinoma}

\section{Introduction and Clinical Features}

Irrespective of the organ or parenchymal structure of origin, adenoid cystic carcinomas of a variety of anatomic sites show slow growth with aggressive local invasion and recurrence, followed only very late in the course of disease by metastatic events. ${ }^{167-}$ 170 The prototypic adenoid cystic carcinoma is a major or minor salivary gland tumor; accessory minor salivary gland-like tissue is seen in the lacrimal apparatus, the upper and lower respiratory tract and rarely in the breast, uterine cervix, thymus and prostate gland. As a primary cutaneous neoplasm, this tumor is rare, with an exceptional case seen in the head and neck, particularly the scalp, and also occasionally on the trunk. A recent report describes its appearance in the external auditory canal. ${ }^{171}$

\section{Histopathology}

In a fashion analogous to the tumor of salivary gland, adenoid cystic carcinoma of the skin forms tubuloalveolar structures lined by atypical basaloid epithelia and associated with the formation of basophilic 'cylinders' of myxoid matrix substance. Globules and cylinders of brightly eosinophilic basement membrane-like material, similar to those described in the cutaneous cylindroma, complete the picture. ${ }^{172-178}$ Mitoses are typically inconspicuous and, as mentioned above, the nuclear morphology is often deceptively bland. An important criterion in adenoid cystic carcinoma in any anatomical location is the striking propensity of these tumors to manifest perineural infiltration. In salivary gland tumors, most authorities are hesitant to make the diagnosis in the absence of this feature. ${ }^{179}$ The same, in our view, applies to the skin. 

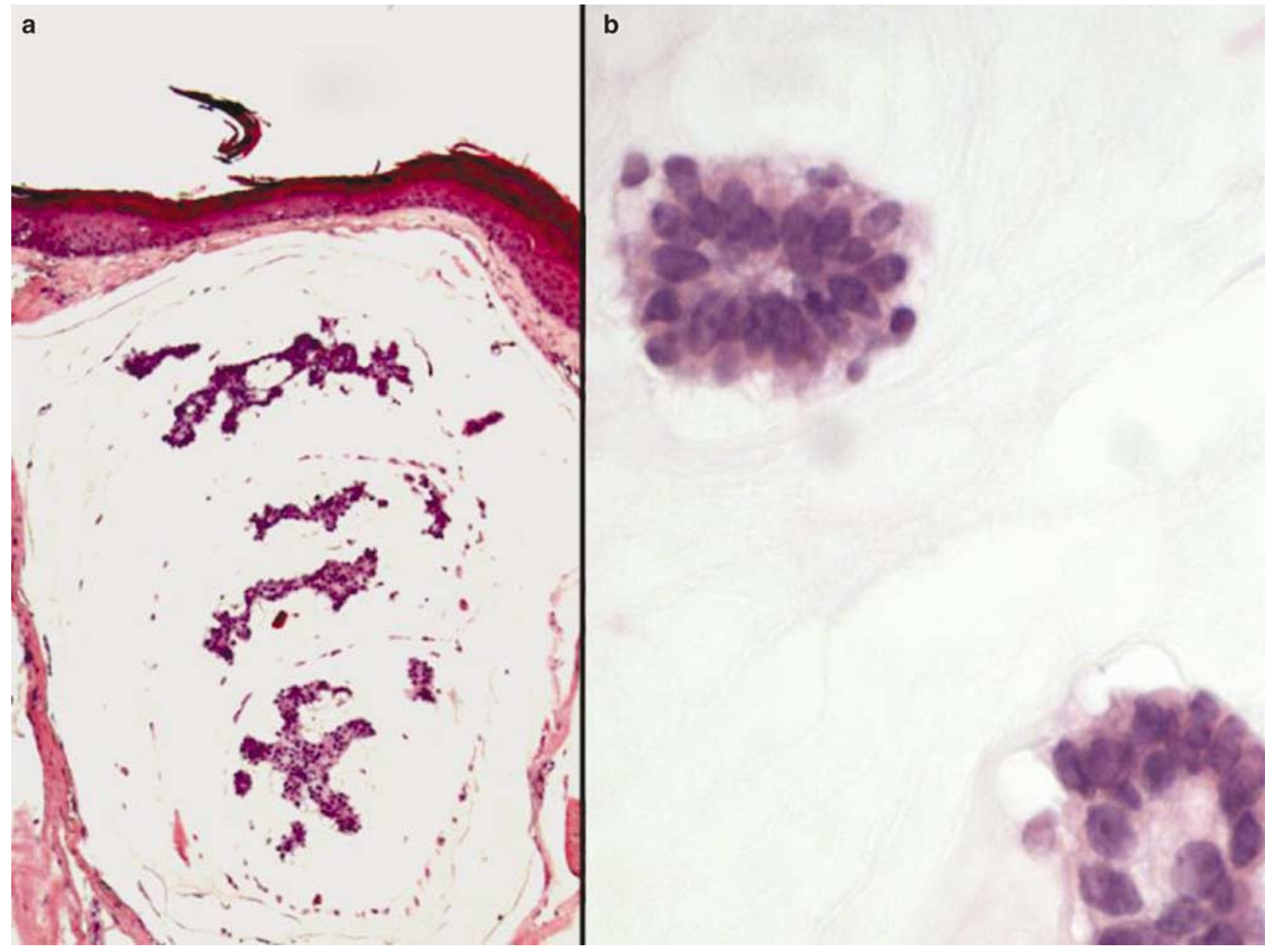

Figure 14 Mucinous eccrine carcinoma. Floating free in pools of mucin (a) are neoplastic columnar epithelia showing often low-grade cytologic epithelia (b). The tumor thus has a morphology cognate to mucinous carcinomas of the gastrointestinal tract and breast.

\section{Differential Diagnosis}

Most basaloid tumors showing cylinders of eosinophilic material and/or myxoid stromal alteration with a tubuloalveolar pattern of growth are in fact BCC showing an adenoid cystic-like or 'adenoid' pattern. These tumors, however, show peripheral palisading at their exterior margin with slit-like retraction from the adjacent stroma, and, in most cases, as this is a form of indolent growth neoplasm, the overall architecture is a nodular one with the absence of irregularly shaped tongues of tumor or stromal desmoplasia. ${ }^{71,176}$ As with most indolent growth BCCs, perineural infiltration would be most unusual in an adenoid BCC. In the center of nodular BCC including the adenoid variant, the tumors typically show apoptosis of individual cells with mitotic figures. These latter features are rare in the adenoid cystic carcinoma of the skin. Furthermore, the indolent growth BCCs may manifest melanin production, which is absent in the adenoid cystic carcinoma, and any form of BCC may show divergent differentiation with the formation of sebaceous, pilar or other structures. Like other forms of eccrine adnexal cancer, the adenoid cystic carcinoma typically expresses EMA, which BCC does not.

\section{Papillary digital eccrine adenocarcinoma}

This is a perplexing form of potentially lethal acral or near-acral adnexal cancer. In addition to high local recurrence, some $50 \%$ of tumors manifest distant metastases, typically to lungs and lymph nodes. As with acral melanomas, amputation at or above the nearest joint is one recommended strategy for local control. ${ }^{180-182}$

\section{Aggressive digital papillary adenoma/ adenocarcinoma}

\section{Introduction}

There is a peculiar group of rare neoplasms which tend to occur in adults on the acral parts, in 
particular the fingers, toes and adjacent skin of the palms and soles, as an isolated solid or solid and cystic mass. Termed aggressive digital papillary adenoma or adenocarcinoma, this lesion presents as a tumefactive nodule on a digit and invades the adjacent soft tissue, but rarely ulcerates. Since the year 2000, the approach taken by pathologists to such neoplasms has undergone a radical change, reflecting novel publications in the peer-reviewed medical literature that in turn reflect the reported experience of national reference centers that deal with patients who develop these rare neoplasms.

\section{Histopathology}

The entity termed 'aggressive digital papillary eccrine adenoma and adenocarcinoma' first appeared in the English language medical literature in 1984. ${ }^{183}$ Papillary eccrine neoplasms in other anatomic locations were recognized prior to their identification in digits and other acral parts. ${ }^{184-187}$ The papillary digital eccrine adenomas and adenocarcinomas typically manifest features of eccrine differentiation by virtue of showing intracytoplasmic lumina and common luminal margins (Figures 15 and 16). The neoplasm is divergent morphologically from the typical eccrine spiradenoma or eccrine acrospiroma and other allied benign eccrine adnexal neoplasms by virtue of showing a papillary or micropapillary architecture cognate to that of insitu papillary carcinomas of ductal structures of the human breast. ${ }^{186,188-196}$ In particular, these neoplasms tend to manifest areas of micropapillary projections protruding into cystically dilated luminal spaces; these micropapillary structures lack fibrovascular cores. The micropapillae comprise tufts of banal or variably atypical low columnar epithelium, sometimes showing apocrine differentiation. This constellation of findings is reminiscent of the intraductal papillomas, atypical papillomas and papillary carcinomas seen in breast ducts. Such areas may merge to form complex sheets of cells associated with stromal invasion. A subset of digital papillary eccrine neoplasms is capable of provoking distant metastatic spread with significant patient morbidity and mortality. Predicting which of these digital eccrine neoplasms belong to the subset

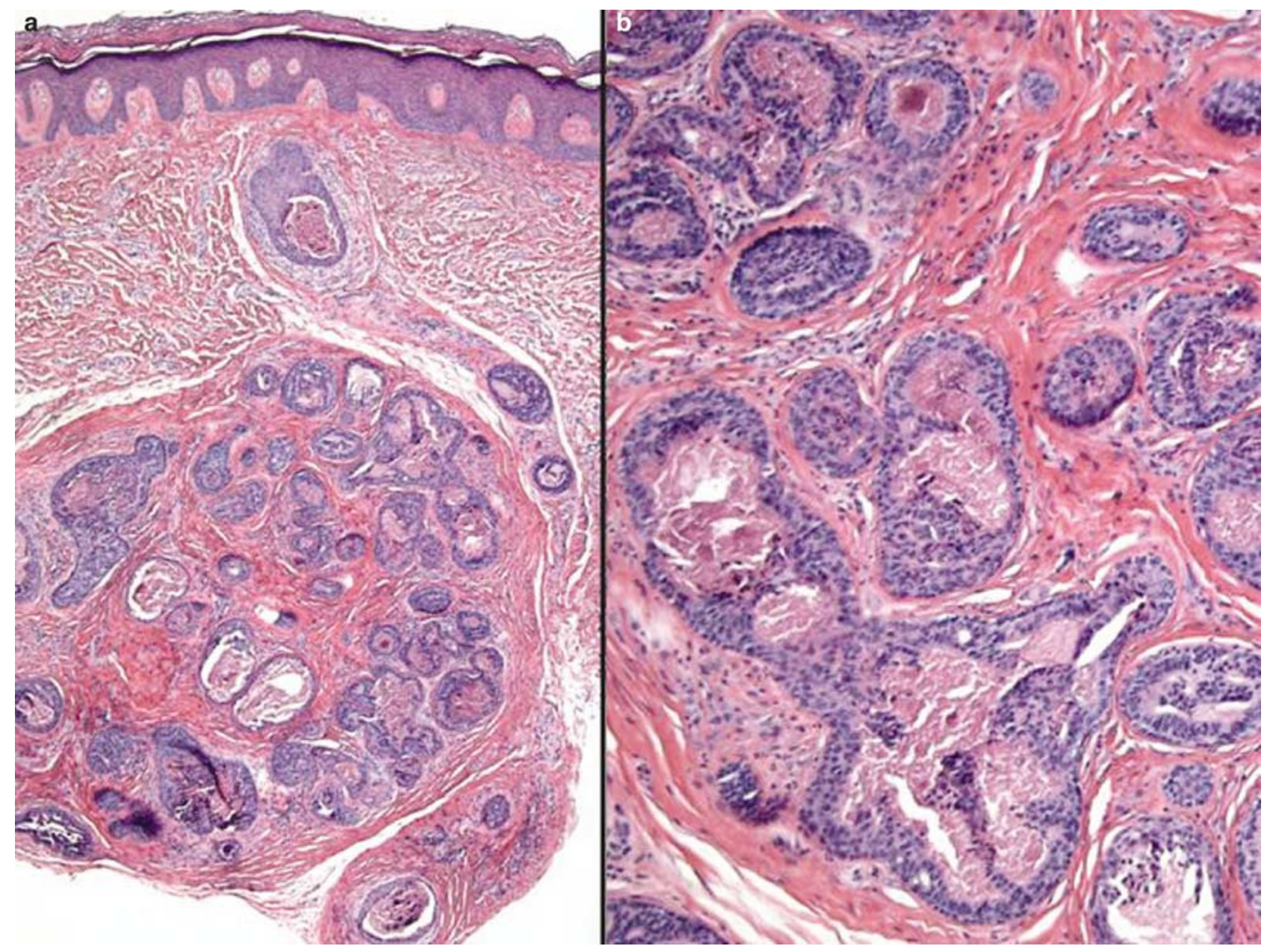

Figure 15 Eccrine digital papillary adenocarcinoma. The low-power morphology of digital papillary eccrine carcinoma (a) is cognate to that of ductal carcinoma in situ of the breast. Within nests of neoplastic columnar epithelia are areas of confluent necrosis (b). 


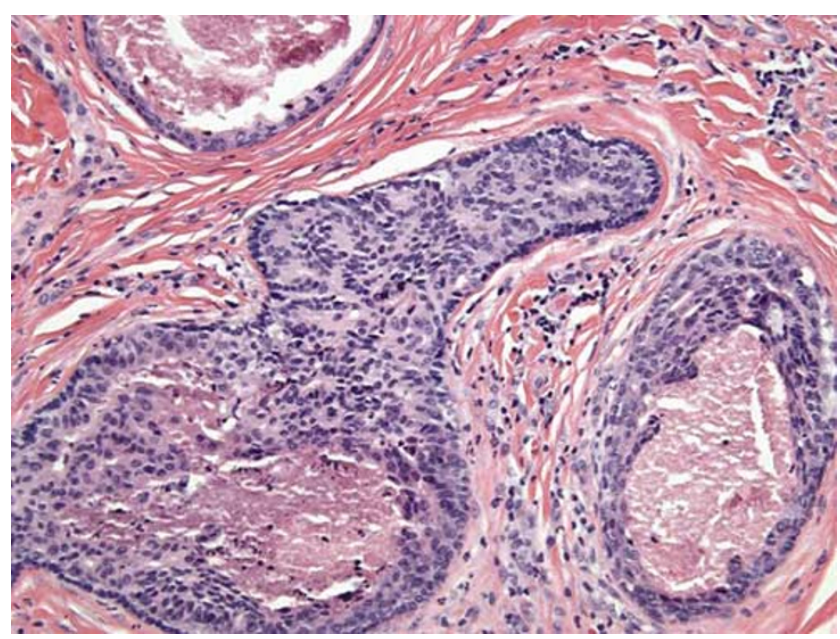

Figure 16 Eccrine digital papillary adenocarcinoma. The neoplastic columnar epithelia form papillary tufts and buds projecting into the dilated lumina of pre-existing eccrine structures. Due to the degree of cytologic atypia, a tumor with this architectural pattern in the breast would be considered an intermediate-grade cribriform/papillary carcinoma despite the abundant intraluminal necrosis.

having a metastatic potential is extremely difficult. The so-called low-grade 'aggressive digital papillary adenoma' is distinguished from the 'high-grade adenocarcinoma' by virtue of the latter showing greater pleomorphism, mitoses and necrosis. Notwithstanding the foregoing, criteria distinguishing benign from malignant eccrine neoplasms have been elusive in the literature. Currently, all such digital eccrine papillary neoplasms are lumped together and are held to have a metastatic potential, albeit the said potential is apparently greater in the more floridly atypical and mitotically active forms. Thus, the term 'aggressive digital papillary adenoma' favored in an earlier era seems soon to be abandoned. Earlier textbooks in the discipline, ${ }^{197}$ and some subspecialty textbooks of skin adnexal neoplasia, ${ }^{151}$ distinguish papillary eccrine adenoma of acral parts from malignant papillary eccrine tumors. In earlier works, most such neoplasms were held to represent adenomas ${ }^{151}$ lacking the capacity to generate distant metastases and/or mortality. However, even prior to 1990, it was recognized that 'at least $40 \%$ of recurrent lesions have regional lymph node and/or pulmonary metastases'. ${ }^{151}$ The challenge of differentiating benign from malignant variants of these tumors is further clouded by the recognized capacity of histologically banal eccrine neoplasms to transform into cancers. ${ }^{198}$ The concept of progressive transformation of benign to malignant proliferations of epithelial and other cell types has long been recognized in other tissues in humans and in animals. It is thus possible, indeed even likely, that some cases of otherwise indolent digital papillary eccrine adenoma undergo malignant transformation as well.

It is now recognized that histologic criteria do not reliably distinguish benign (adenoma) from malig- nant (adenocarcinoma) in acral digital papillary eccrine adnexal neoplasms. ${ }^{199}$ Duke's paper specifically addresses and refutes the work of Kao et $a{ }^{200}$ who felt that criteria existed to distinguish aggressive digital papillary adenoma from aggressive digital papillary adenocarcinoma histologically. In the hands of Kao et al, poor gland differentiation, necrosis, cytologic atypia, mitotic rates and invasion of soft tissue, bone or blood vessels were features that distinguished adenocarcinoma from adenoma. Despite the foregoing, the concept of papillary eccrine adenoma has persisted into the common era. ${ }^{201-203}$

\section{Management}

Management of the aggressive digital papillary adenoma and adenocarcinoma remains a controversial issue, with some authors advising digital amputation. ${ }^{180}$ In addition to high local recurrence, some $50 \%$ of tumors manifest distant metastases, typically to lungs and lymph nodes. As with acral melanomas, amputation at or above the nearest joint is one recommended strategy for local control. ${ }^{180-182}$ In part because of the rarity of these tumors, modern surgical approaches such as sentinel lymphadenectomy that are commonplace for melanomas are reportable as isolated cases when applied to the digital papillary eccrine tumors. ${ }^{204,205}$ Currently, the use of aggressive local surgical extirpation is generally advised for any digital papillary eccrine neoplasm as the 'originally proposed criteria for distinguishing benign (adenoma) and malignant (adenocarcinoma) do not necessarily predict biological behaviour'. ${ }^{205}$

\section{Differential Diagnosis}

Differential diagnostic considerations include the microcystic adnexal carcinoma, hidradenoma papilliferum, syringocystadenoma papilliferum and the nipple adenoma. Microcystic adnexal carcinoma shows thin vertically and haphazardly oriented columns of variably atypical epithelia surmounted by keratinizing microcysts with a granular cell lining internally. It therefore lacks the architectural organization of the papillary eccrine and apocrine neoplasms and also does not show apocrine differentiation. Stromal desmoplasia is frequent in the microcystic adnexal carcinoma and is not seen in the digital papillary neoplasms of benign character. In contrast, the digital papillary adenocarcinomas of increasing dedifferentiation show irregularly shaped and sized nests associated with pronounced stromal fibroplasia, in concert with abundant endolumenal necrosis, overt nuclear anaplasia and mitotic activity. These large tubulopapillary structures are thus strikingly different and simultaneously more cytologically atypical than the microcystic adnexal carcinoma, and should be easily distinguished even 
at scanning magnification. As mentioned above, they have more in common morphologically with in-situ ductal breast carcinoma than with the indolent or low-grade eccrine neoplasms. Hidradenoma papilliferum typically seen in areas of high apocrine gland concentration, such as the vulva, perineum and the axillae, exhibits large structures with a rounded peripheral contour containing papillary proliferations of apocrine epithelium lacking cytologic atypia, necrosis or mitotic activity. The syringocystadenoma typically opens to the epidermal surface, as seen in the setting of an underlying nevus sebaceus, and manifests banal apocrine epithelium admixed with cuboidal cells covering fibrovascular stromal cores which are rich in plasma cells. The nipple adenoma may also open to the epidermal surface to form the so-called 'erosive adenoma', and is morphologically similar to syringocystadenoma papilliferum. Furthermore, the hidradenoma papilliferum is confined, in the great majority of cases, to women. As mentioned above, the distinction of a benign eccrine papillary neoplasm from one with a metastatic potential is extremely difficult and, in the view of some authorities, impossible.

\section{Microcystic adnexal carcinoma}

\section{Introduction}

This tumor is alluded to above. Typically a neoplasm of the mid-face of young, middle-aged or elderly woman, it has a tendency toward persistent and stubborn local recurrence, but not to metastatic deposits. ${ }^{182,206-209}$ In particular, the upper lip and the glabella are common locations; rarely, tumors appear outside the head and neck in locations such as the axilla. Local recurrence rates are approximately $50 \% .^{210-214}$ Occasionally, the lesion will appear in unusual locations and settings, such a recent case arising in the external auditory canal 15 years after radiotherapy of a nasopharyngeal carcinoma that had occurred in a 12-year boy. ${ }^{215}$ Another patient showed the synchronous development of a microcystic adnexal carcinoma with a gastric carcinoma. ${ }^{216}$

A synonym for these tumors is sclerosing syringomatous carcinoma or sclerosing sweat duct carcino$m a$, which encompasses not only the neoplastic epithelia but also makes reference to the stromal desmoplasia, which is a frequent concomitant of these tumors. Currently, many microcystic adnexal carcinomas are treated with Mohs' surgery. ${ }^{217}$

\section{Histopathology}

The prototypic microcystic adnexal carcinoma comprises tubules of rather banal eccrine ductal epithelium, often compressed into a single column of cells, which are vertically and haphazardly oriented in the reticular dermis extending out to the peripheral margins of a punch biopsy specimen (Figures 1719). Surmounting the vertically oriented tubules in the papillary dermis are microcysts comprising keratinizing stratified squamous epithelia with a granular cell layer and encompassing central keratin (Figure 18). The so-called sclerosing sweat duct carcinoma lacks these putative pilar microcysts $^{218,219}$ and, in their absence, that designation, or in the presence of high-grade cytologic anaplasia, the terms anaplastic syringoma or syringoid carcinoma have also been applied. ${ }^{220,221}$ Neoplastic cells may infiltrate blood vessels, skeletal muscle and perineural spaces. ${ }^{153,222-228}$ Concentric whorls of tumor cells and clear cell change are described. ${ }^{229}$ Inspisated secretory material and an internal lining cuticle expressing CEA (Figure 20) give evidence to eccrine differentiation in these neoplasms. ${ }^{218}$ Expression of mutant p53, c-erbB-2, bcl2, and Ki-67 is typically not observed. ${ }^{230}$

\section{Differential Diagnosis}

The differential diagnosis of microcystic adnexal carcinoma is that of the sclerosing adnexal neoplasms of the head and neck. These are commonly

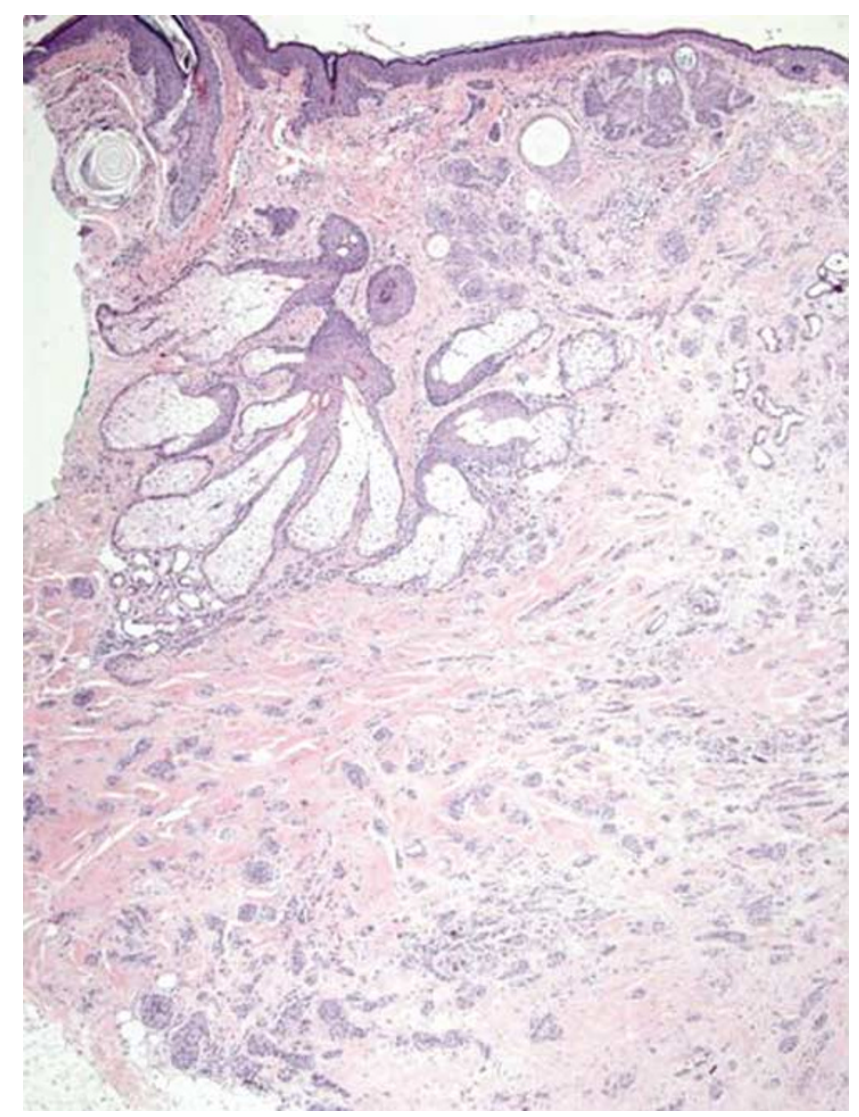

Figure 17 Microcystic adnexal carcinoma. In this low-power micrograph, tumor infiltrates widely through a $4 \mathrm{~mm}$ punch biopsy to the deep and transverse edges of the tissue sample. 


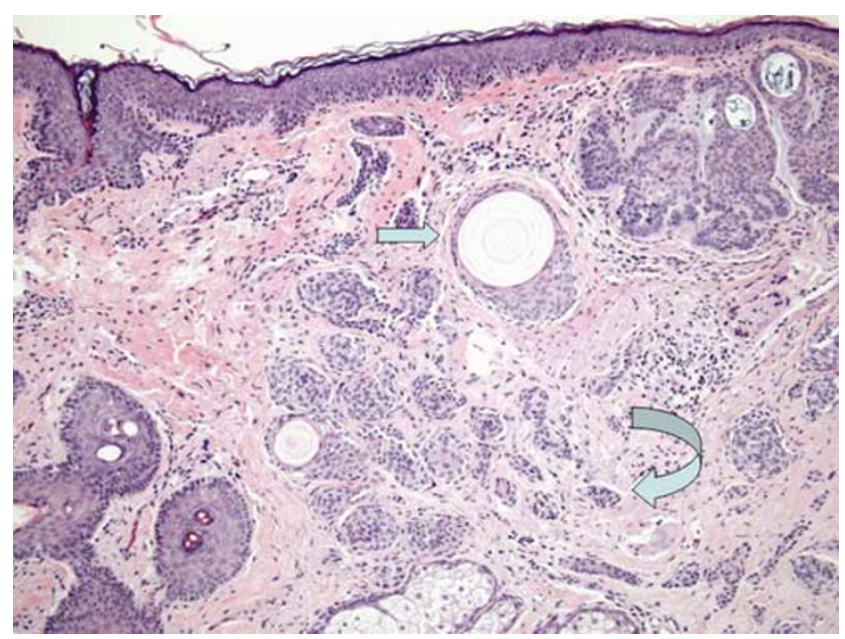

Figure 18 Microcystic adnexal carcinoma. In the superficial dermis are microcysts of keratinous debris surrounded by squamous epithelia (straight arrow) showing keratohyalin granules in some foci. These keratinous microcysts surmount neoplastic tubules (curved arrow), which grow in a haphazard fashion through a desmoplastic stroma.

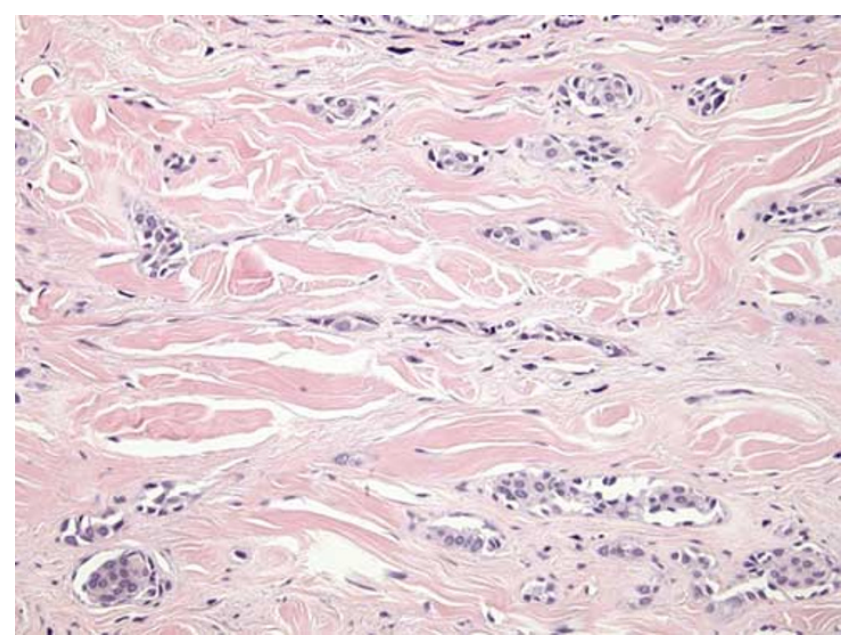

Figure 19 Microcystic adnexal carcinoma. The tumor tongues form narrow columns that grow through a desmoplastic stroma.

held to include the desmoplastic trichoepithelioma, the sclerosing or morpheaform BCC, the syringoma and those rare forms of basosquamous or poorly differentiated squamous cell carcinoma of the skin that show intracytoplasmic vacuolation suggesting gland formation, that is, the so-called adenosquamous carcinoma of the skin. Some authors rank trichoadenoma in the differential diagnosis list for microcystic adnexal carcinoma, but in our view this is a distinction that can be made at the light microscopic level with comparative ease. The desmoplastic trichoepithelioma typically presents as a small mid-facial papule or as multiple small firm papules as distinct from the ill-defined plaque of microcystic adnexal carcinoma. ${ }^{218,231,232}$ This clinical morphology has a histologic analog; in

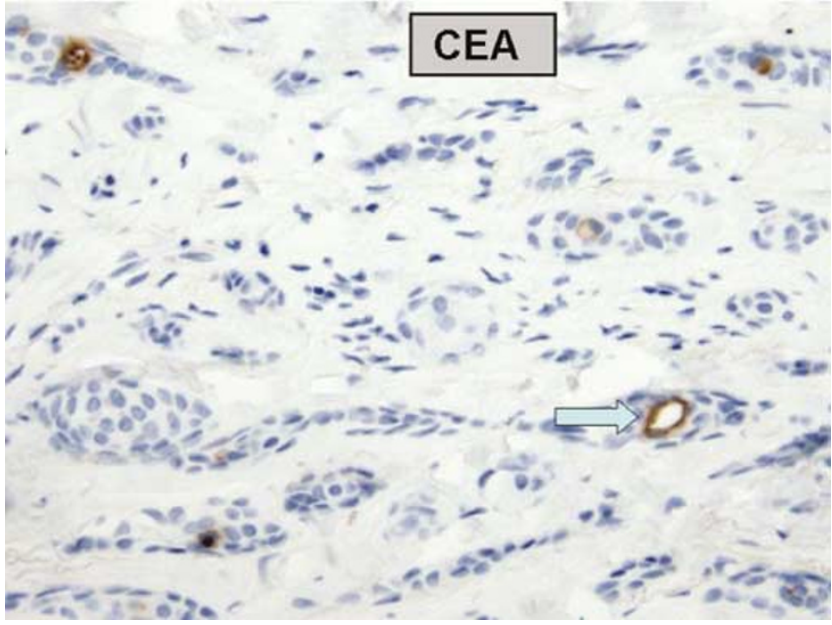

Figure 20 Microcystic adnexal carcinoma: CEA immunohistochemistry. The intracytoplasmic lumina decorate strongly with CEA (arrow) in this example of a microcystic adnexal carcinoma.

particular, the microcystic adnexal carcinoma is widely invasive to the edges of a $5-\mathrm{mm}$ punch biopsy specimen, whereas the desmoplastic trichoepithelioma might well be completely encompassed by a biopsy of this size. Put another way, the desmoplastic trichoepithelioma is a shallow tumor, whereas the microcystic adnexal carcinoma invades deeply. Like conventional trichoepithelioma, the desmoplastic form has its own modified specialized stroma and, if the peripheral contour of the lesion and its interface with adjacent native dermis is identified, it has a circumscribed morphology as opposed to the ill-defined and poorly circumscribed margin of a microcystic adnexal carcinoma. Desmoplastic trichoepithelioma is often associated with horn cysts, several of which may have ruptured into the adjacent stroma with cholesterol clefts and their associated foreign body granulomatous inflammatory response. Like conventional trichoepithelioma, mitoses and individual cell necrosis should be absent. The desmoplastic trichoepithelioma may show slit-like retraction of the tumor plus the adjacent peritumoral mesenchyma from nearby stromal cells. This is distinctive from the morpheaform BCC and from the microcystic adnexal carcinoma, which characteristically does not show stromal retraction change. Trichoepithelioma is characteristically banal cytologically, but this feature does not permit a distinction from the often low-grade nuclear atypia seen in microcystic adnexal carcinoma. In contrast to the foregoing, the sclerosing or morpheaform BCC shows slit-like retraction of tumor cells from the immediately adjacent stroma. Mesenchymal mucosubstances are often present in these slit-like areas of stromal retraction. ${ }^{233}$ Mitoses are identified in morpheaform BCC, but may be hard to find as the tumor volume relative to stroma is often low. Individual cell necrosis should be apparent, however. Morphea- 
form BCC often forms part of an infiltrative growth tumor with larger, jagged and irregular nests, and is associated with stromal desmoplasia, the fibroblasts in the mesenchymal component being plump and proplastic. Finally, there may be a component of coexistent nodular or superficial BCC, which clinches the diagnosis. With respect to syringoma, these lesions show multiple layers of ductal epithelia, comma-shaped tales and central inspisated mucosubstances. The tubular character of the syringoma and its multilayered ductal elements should enable distinction. Like the desmoplastic trichoepithelioma, it is more shallow and broad in character than the microcystic adnexal carcinoma. Shave biopsies from this group of lesions which do not sample the tissue edges and the deep lesional margin can create diagnostic difficulties, particularly when a clinical history is not provided with the specimen. ${ }^{143}$ One type of syringoma, namely that observed as a manifestation of multiple heritable syringomas, can extend deeply and can be confused with a microcystic adnexal carcinoma. In the heritable variant, there is always a well-defined pattern of cellularity with cells forming multiple layers around ductal elements. Also, there is a definite stroma that accompanies the cellular proliferative areas as in the common syringoma. Furthemore, there is no evidence of neurotropism. ${ }^{234,235}$ A lesion termed syringomatous adenoma of the nipple ${ }^{236}$ seen in both sexes, is held to be a form of microcystic adnexal carcinoma occurring outside the head and neck region. ${ }^{143}$ The so-called primary adenosquamous carcinoma of skin connects to the overlying epidermis from which radiate cytologically malignant epithelia, forming intercellular bridges in concert with a glandular component comprising common lumenal margins and/or intracytoplasmic lumens. Mitoses and individual cell necrosis are a frequent finding, the latter often forming confluent zones of geographic necrosis. The tumor extends from the epidermis across a broad front and may show both perineural and vascular invasion. ${ }^{237-240}$

\section{Mucoepidermoid carcinoma of the skin}

\section{Introduction and Clinical Features}

In a fashion analogous to the adenoid cystic carcinomas primary in the skin, the mucoepidermoid carcinoma is a neoplasm which recapitulates that seen in major and minor salivary glands in diverse anatomic locations. ${ }^{241-243}$ Like adenoid cystic carcinoma in salivary gland tissue, the mucoepidermoid carcinomas in that tissue anlage tends to show multiple local recurrences and only uncommonly distant metastases; in such a scenario, the clinical history provides definitive proof. ${ }^{244-247}$ Mucoepidermoid carcinoma has been reported to arise in a nevus sebaceus of Jadassohn. ${ }^{248}$ As is the case with many of the adnexal carcinomas, Mohs microsurgery had been advocated in the treatment of mucoepidermoid carcinoma of the skin. ${ }^{249}$

\section{Histopathology}

Like their counterparts in salivary gland tissue, the primary mucoepidermoid carcinomas of the skin show an admixture of squamous epithelial elements which may be deceptively bland, associated with areas of glandular differentiation comprising low columnar mucin-containing cells often associated with mucin-containing microcysts. ${ }^{241-243}$ Clear cell change may be seen. ${ }^{247}$ Unlike the adenoid cystic carcinoma, perineural infiltration is rare ${ }^{143}$ Cytologic atypia is inconspicuous, with round to oval nuclei in the 10-15- $\mu \mathrm{m}$ size range, showing little if any apoptosis and typically no mitoses. ${ }^{250}$ These banal cytologic characteristics exclude forms of metaplasia occurring in typical squamous cell carcinoma. ${ }^{250}$

\section{Differential Diagnosis}

The main diagnostic consideration would be a metastasis from a mucoepidermoid carcinoma. Prototypically, this would occur in the head and neck area. Criteria for distinguishing these two events would then become important. The presence of inflammation is said to favor a primary mucoepidermoid carcinoma as does a solitary lesion, and a uninodular as opposed to multifocal pattern of growth. ${ }^{143}$ By direct extension from minor salivary gland tissue in the oral cavity and its analogs in the nasopharynx or the lacrimal apparatus, mucoepidermoid carcinoma involving the skin would grow from the subcutaneous tissue and/or skeletal muscle vertically towards the skin surface, typically sparing the upper reticular and papillary dermis as well as the epidermis. In contrast, a primary mucoepidermoid carcinoma of the skin taking origin from the sweat apparatus would dominantly be centered in reticular dermis or at the dermal-subcutaneous interface. The problem of squamous syringometaplasia is less significant as the degree of atypia is typically less in this scenario; there should be evidence either of a surgical insult or of individual cell necrosis of the eccrine apparatus due to chemotherapy and/or neutrophilic hidradenitis. ${ }^{251}$ Furthermore, a clinical history of previous cancer with appropriate chemotherapy should be available if the appropriate questions are asked. At times mucoepidermoid carcinoma may be confused with adenosquamous carcinoma. Differentiation can be made on the basis of the presence of pancytokeratin, CK 7, CEA and EMA positivity, and CK 20 and GCDFP negativity. These findings indicate that this carcinoma is of adnexal as opposed to epidermal cell origin. ${ }^{252}$ 


\section{Carcinoma arising in pre-existing cylindroma or eccrine spiradenoma}

\section{Introduction and Clinical Features}

Malignant degeneration of pre-existing benign eccrine adnexal tumors is a well-described phenomenon $^{198,253-269}$ and is heralded by a sudden change in tumor size or the acquisition of symptomatology such as pain or ulceration.

\section{Histopathology}

In order to be considered a bona fide finding, the pre-existing benign neoplasm must be identifiable. The malignant degeneration is typically characterized by sheets of undifferentiated carcinoma cells showing loose cohesion, whereby the tumor cells have high-grade nuclear atypia. The tumor may form sheets of polygonal cells with abundant eosinophilic cytoplasm, spindled areas or admixtures of the foregoing. Mitoses and individual cell necrosis are a common finding and there may be zones of geographic necrosis as well. ${ }^{143,254,257}$ In consequence of the foregoing, the tumor may have either pure squamous, adenosquamous, glandular or sacromatoid features. These changes do not necessarily herald imminent metastatic behavior. ${ }^{259,262,263} \mathrm{~A}$ hybrid tumor exhibiting the features of a malignant cylindroma and of a malignant spiradenoma has been described in two patients; the authors held that elevated p53 expression and increased nuclear staining with Ki-67 can be useful in distinguishing benign from malignant appendage tumors. ${ }^{132}$

\section{Eccrine ductal adenocarcinoma}

\section{Introduction and Clinical Features}

Eccrine ductal adenocarcinoma is so named because it histologically mimics the ductal carcinomas of the breast. ${ }^{127,220,270}$ Clinical history then becomes essential to proper interpretation. ${ }^{143}$ This primary skin tumor is typically a slow-growing lesion up to $5 \mathrm{~cm}$ in diameter, present for months or years prior to presentation. It is therefore quite distinctive from secondary deposits of breast cancer in the skin, which typically occur either in the skin of the ipsilateral anterior chest wall or axilla, or occur as multiple disseminated metastatic seeds in a widespread disposition. ${ }^{270,271}$ Like primary breast cancers and like the aggressive digital papillary adenoma/ low-grade papillary adenocarcinoma of the digits, primary ductal eccrine adenocarcinoma is an aggressive tumor that has a high risk of disseminated metastatic seeding.

\section{Histopathology}

The eccrine ductal adenocarcinoma is characterized by solid sheets and cords of cells forming true common lumenal margins with tubuloalveolar formations, papillary components and areas of obvious infiltration of a desmoplastic stroma. ${ }^{169,272-276}$ In the primary location, carcinoma in situ of the eccrine straight ducts and of the secretory coil may be demonstrated in a fashion analogous to high-grade in-situ ductal carcinoma of the breast. ${ }^{272} \mathrm{~A}$ further analogy with breast cancer is the presence of a parallel immunohistochemical profile including in the context of estrogen and progesterone hormone receptors. ${ }^{277,278}$ The foregoing necessitates correlation to a comprehensive and accurate clinical history. Areas of squamous differentiation may be seen in the eccrine ductal adenocarcinoma. Some forms show a fibromyxoid stroma, which has caused some authorities to label such lesions malignant chondroid syringoma, ${ }^{189,272}$ while others use the term eccrine adenocarcinoma with fibromyxoid stroma. ${ }^{189,272}$ These lesions may connect to the epidermal surface and so mimic forms of basal cell or squamous cell carcinoma with myxoid stroma, but invariably express EMA, enabling distinction. ${ }^{189,278}$ These tumors may collide with other forms of primary eccrine cancer.

\section{Differential Diagnosis}

As implied by the histomorphology, the differential diagnosis of the eccrine ductal adenocarcinoma is in fact a metastatic deposit of ductal carcinoma of the breast, which can be distinguished by clinical history in most cases.

\section{Clear cell eccrine carcinoma}

\section{Introduction}

On occasion, a malignant neoplasm with obvious eccrine features will show an overwhelming or universal clear cell cytoplasmic morphology. The designation clear cell eccrine carcinoma is then applied. ${ }^{279,280}$ The clinical behavior and nosology are similar to those of the malignant acrospiroma or hidradenocarcinoma; ${ }^{272,281-287}$ the abundant clear cell change gives the tumor a distinctive histomorphology and differential diagnosis.

\section{Clinical Features}

The tumors present typically as a solid nodular growth in the head and neck region up to $5 \mathrm{~cm}$ in greatest diameter.

\section{Histopathology}

Skin biopsies show a multinodular dermal proliferation with no connection to the overlying epidermis. The critical cells have abundant clear cytoplasms, neoplastic nuclei that may either be 
low grade with round to oval nuclei manifesting smooth contours, or more atypical features with irregular clearing of chromatin and irregular thickening of the chromatinic rim. The tumor masses form broad sheets separated by a fibrovascular stroma. The mitotic count is variable, with no defined threshold for diagnosis. Similarly, necrosis may be absent or may manifest as individual cell necrosis and occasionally as confluent or geographic necrosis. Some cases show perineural or vascular invasion. ${ }^{279,280}$

\section{Differential Diagnosis}

The differential diagnosis of malignant clear cell neoplasms in the skin includes metastases from clear cell tumors of thyroid, kidney, and rarely from lung. ${ }^{270,288}$ The metastatic renal cell tumors often have granular debris in their stroma and a finely arborizing vascular pattern. In the modern era, the use of antibodies to TTF enables easy distinction of pulmonary primary large cell carcinomata in which TTF is almost uniformly expressed, from those clear cell carcinomas primary in the skin in which TTF studies are negative. A proportion of clear cell neoplasms of ovary, kidney and endometrium may have a hobnail pattern which is absent in the primary cutaneous clear cell carcinoma. ${ }^{270,288-290}$ As with other eccrine cancers, the clear cell variant expresses CEA, which is uniformly negative in renal cell cancer and typically is also not expressed in neoplasms of ovary and endometrium. ${ }^{278}$

\section{Carcinosarcoma}

\section{Introduction}

Although occasional cases of fully transformed malignant neoplasms arising in cutaneous mixed tumors are reported, ${ }^{291}$ the term malignant mixed tumor is reserved for neoplasms showing divergent differentiation with both epithelial and mesenchymal cell lines demonstrated. ${ }^{143,291-302}$ Carcinosarcoma has been reported to arise in a patient with multiple cylindromas. ${ }^{303}$

\section{Clinical Features}

In the typical setting of a pre-existing indolent nodule, a patient reports rapid change with growth, ulceration and sometimes tenderness. Despite a histopathology suggesting an aggressive neoplasm, most behave in a biologically indolent fashion.

\section{Histopathology}

The typical malignant mixed tumor comprises a neoplasm in which areas of recognizable eccrine differentiation are admixed with neoplastic me- senchymal elements, be they of chondrosarcoma, rhabdomyosarcoma, leiomyosarcoma, osteosarcoma or fibrosarcoma types or undifferentiated sarcomatous proliferations. ${ }^{292-302}$ In a case of carcinosarcoma arising in a cylindroma, there were both clearly malignant adnexal epithelia as well as a sarcomatous area with malignant spindle cells. ${ }^{303}$

\section{Differential Diagnosis}

True carcinosarcomas of breast, lung and other sites can involve the skin by direct extension or by metastatic seeding. ${ }^{304}$ These neoplasms prove difficult to differentiate from primary cutaneous malignant mixed tumors. With respect to pulmonary disease, application of TTF immunohistochemistry has not yet been reported in the literature to our knowledge, but this seems a logical course.

\section{Basaloid eccrine carcinoma}

\section{Introduction}

A tumor of historical note, basaloid eccrine carcinoma, was first reported in $1968^{220,305}$ in a series of cutaneous neoplasms, some of which likely represent, in hind sight, Merkel cell carcinoma. ${ }^{306}$ More recently, a small cell or basaloid variant of eccrine cancer has been described, ${ }^{307}$ which appears to represent a bona fide entity. ${ }^{307}$

\section{Clinical Features}

In the experience of Wick et al, ${ }^{143}$ these tumors are invariably acral neoplasms of longstanding which, at least in some, have proven capable of producing metastatic deposits in lymph nodes and, in at least one case, fatal dissemination to the viscera.

\section{Histopathology}

Nests and cords of monotonous small basaloid cells with hyperchromatic nuclei showing frequent and atypical mitoses, individual cell and confluent necrosis, and sparse cytoplasms mimicking neuroendocrine carcinoma typify this tumor. Areas of confluent necrosis lead to microcyst formation. The stroma may be desmoplastic in nature.

\section{Differential Diagnosis}

The differential diagnosis of the basaloid eccrine carcinoma includes the 'small round blue cell tumors', including the Merkel cell carcinoma, Ewing's sarcoma, mesenchymal chondrosarcoma, lymphoma and small cell melanoma ${ }^{308}$ or basaloid squamous cell carcinoma. With respect to these differential diagnostic considerations, Merkel cell carcinomas express chromogranin and synaptophy- 
sin, Ewing's sarcoma expresses CD99 and contains abundant cytoplasmic glycogen, lymphomas typically express common leukocyte antigen (CD45) and small cell melanoma in most cases is $\mathrm{S} 100$ positive, but may also decorate for melanocyte lineagespecific markers such as melan-A and HMB-45. Squamous cell carcinomas, as described above, typically do not express CEA.

\section{Paget's disease}

\section{Introduction}

In the past, Paget's disease of the breast, and in particular of the nipple, the so-called mammary Paget's disease, was held to derive from neoplastic transformation of the breast ductal system with secondary extension to the skin. In contrast, extramammary Paget's disease was thought to represent a neoplasm arising in the germinative cells of the basal layer of the epidermis. ${ }^{309,310}$ Both processes were held to manifest apocrine differentiation, but both were held to have different paths of lesional development. However, there are cases of mammary Paget's disease lacking underlying ductal carcinoma of the breast, ${ }^{311,312}$ and further we have seen lesions of extra-mammary Paget's disease with underlying sweat gland carcinoma (personal observation). An alternative cell of origin, the clear cell of Toker, represents the termination of mammary and mammary-like ducts in the nipple and vulva, and has been postulated as a potential alternative progenitor cell. $^{313}$

\section{Clinical Features}

Irrespective of anatomic location, tumors present as erythematous plaques with a scaling or exudative surface. Paget's disease of the breast involves women who most often have an underlying ductal carcinoma and, as one might expect, presentations are typically greater than 40 years of age. Extramammary Paget's disease occurs with an almost equal sex distribution and appears to be concentrated in anatomical sites where apocrine glands manifest greatest density, that is, the vulva, scrotum, perineum, axillae, perineal region, eyelids and the ear canals. Lesions of extrammary Paget's disease have been reported in association with condyloma accuminatum. ${ }^{314}$

\section{Histopathologic Features}

In Paget's disease, the epidermis manifests a proliferation of single and clustered neoplastic cells showing evidence of glandular differentiation. The nuclei are round to oval with prominent nucleoli and dispersed chromatin; typically, the nuclear diameters are up to double those of adjacent keratinocyte nuclei. The glandular differentiation takes the form of intracytoplastic lumina manifesting a basophilic cytoplasmic hue, sometimes with a sharply demarcated intracytoplasmic cuticle. The glandular epithelia may also cluster together to form common luminal margins (Figure 21). On occasion, the cytoplasm shows fine vacuolation. ${ }^{315-320}$ For reasons not understood, the neoplastic glandular cells in Paget's disease often spare the basal layer of the epidermis and appear to compress it from above (Figure 21). As the neoplastic cells have less welldefined intercellular bridges than keratinocytes, they form loosely cohesive groups in a fashion that may mimic an acantholytic process. A rare example of Paget's disease shows marked variation of nuclear size and shape with less conspicuous glandular differentiation; this has been termed anaplastic Paget's disease. ${ }^{321}$ The neoplastic cells in any event contain cytoplasmic epithelial mucins that decorate with alcian blue-PAS, PAS-diastase and mucicarmine preparations. Histochemically, the tumors express gross cystic disease fluid protein-15 (GCDFP-15), as would be anticipated in light of their apocrine lineage, ${ }^{322}$ in concert with CK 7 and CEA. ${ }^{323-326}$ Androgen receptors and Her2/ neu are commonly expressed in both extramammary and mammary Paget's disease, while estrogen and progesterone receptors are not; ${ }^{327}$ Her-2/ neu overexpression ${ }^{328}$ implicates a potential therapeutic role for the Her-2/neu receptor blocker trastuzumab. ${ }^{329}$

\section{Differential Diagnosis}

Neoplasms that show pagetoid migration of malignant epithelia include clonal Bowen's disease, sebaceous carcinoma and melanomas, particularly of superficial spreading type. With respect to superficial spreading melanoma, the presence of melanin granules in the cytoplasms of the neoplastic cells is an important clue to diagnosis, but we have seen cases of pigmented Paget's disease and pigmented Bowen's disease containing melanin granules provided by nurse melanocytes to the neoplastic cells. Thus, one must fall back upon immunohistochemical methods to delineate these lesions. Melanomas express melanocyte lineagespecific markers such as HMB-45 and Melan-A, vs the expression of GCDFP-15, CK 7 and CEA in Paget's disease. ${ }^{323-326}$ Bowen's disease, in contrast, will express high-molecular-weight CK but not CK7 , and should not express any of the aforementioned melanocyte or apocrine lineage differentiation markers. In addition to positivity for CK-20, glandular neoplasms of the genitourinary or gastrointestinal tract (ie endocervix, urachus, or colorectum) may cause diagnostic confusion. ${ }^{330-333}$ Extramammary Paget's disease does not express estrogen or progesterone receptor antigenicity, but has been shown to express androgen receptor proteins as discussed above. ${ }^{334,335}$ Differential expression of 


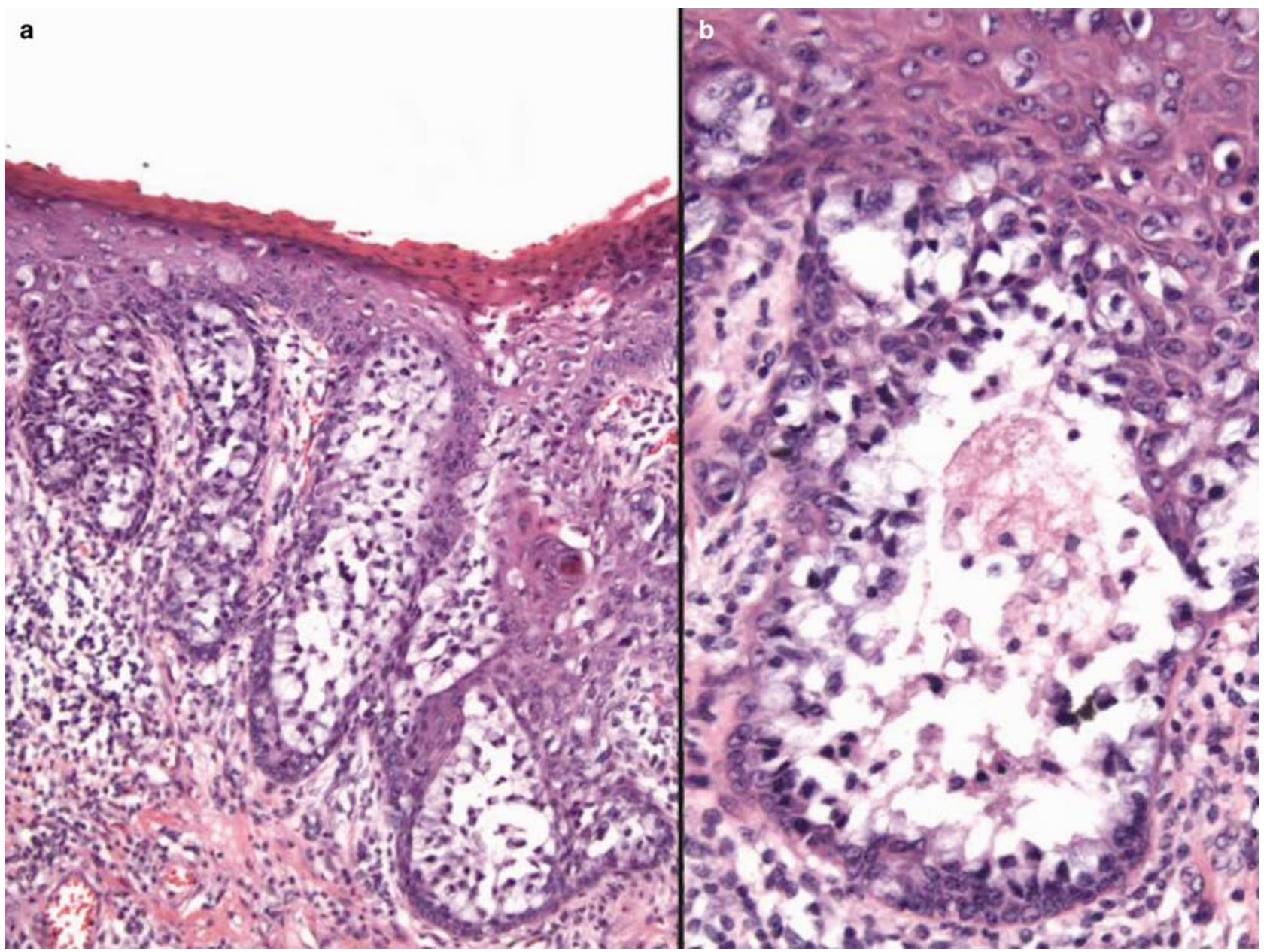

Figure 21 Extramammary Paget's disease. In extramammary Paget's disease, the squamous epithelium is replaced by loosely cohesive groups of neoplastic glandular epithelia (a). The neoplastic glandular epithelia appear to compress the basal layer of squamous epithelium from above (b).

claudins, proteins involved in tight junction assembly in epithelial and endothelial cells, may differentiate cells of Paget's disease from adjacent squamous epithelia, but not from breast carcinoma cells. ${ }^{336}$ Another form of Pagetoid intraepidermal carcinoma with vacuolated cells is sebaceous carcinoma, but in this entity the cells appear vacuolated, with a clear cytoplasmic morphology as opposed to basophilic mucin. It has been shown that CD5 will strongly decorate both Paget's and extramammary Paget's disease, but will not react with cells of Bowen's disease, melanoma in situ or sebaceous carcinoma ${ }^{337}$ Other immunochemical markers such as the T-antigen expressed in sebaceous carcinoma are discussed in the section on tumors of the pilosebaceous apparatus.

\section{Acknowledgement}

Julie Blount of Tulsa, OK provided expert transcription service.

\section{References}

1 Lever WF. Sebaceous adenoma. Review of the literature and report of a case. Arch Dermatol 1948;57:102-111.

2 Warren S, Warvi WN. Tumors of sebaceous glands. Am J Pathol 1943;19:441-460.

3 Prioleau PG, Santa Cruz DJ. Sebaceous gland neoplasia. J Cutan Pathol 1984;11:396-414.

4 Rulon DB, Helwig EB. Cutaneous sebaceous neoplasms. Cancer 1974;33:82-102.

5 Brownstein MH, Shapiro L. The pilosebaceous tumors. Int J Dermatol 1977;16:340-352.

6 Mehregan AH, Rahbari H. Benign epithelial tumors of the skin. II. Benign sebaceous tumors. Cutis 1977;19:317-320.

7 Reiffers J, Laugier P, Hunziker N. Sebaceous hyperplasias, keratoacanthomas, epitheliomas of the face, and cancer of the colon: a new entity? Dermatologica 1976;153:23-33.

8 Rulon DB, Helwig EB. Multiple sebaceous neoplasms of the skin: an association wtih multiple visceral carcinomas, especially of the colon. Am J Clin Pathol 1973;60:745-753. 
9 Sciallis GF, Winkelmann RK. Multiple sebaceous adenomas and gastrointestinal carcinoma. Arch Dermatol 1974;110:913-916.

10 Housholder MS, Zeligman I. Sebaceous neoplasms associated with visceral carcinomas. Arch Dermatol 1980;116:61-64.

11 Tschang TP, Poulos E, Ho CK. Multiple sebaceous adenomas and internal malignant disease: a case report with chromosomal analysis. Hum Pathol 1976; 7:589-594.

12 Fahmy A, Burgdorf WHC, Schosser RH, et al. Muir-Torre syndrome. Reevaluation of the dermatological features and consideration of its relationship to the family cancer syndrome. Cancer 1973;49: 1898-1903.

13 Burgdorf WHC, Pitha J, Fahmy A. Muir-Torre syndrome. Histologic spectrum of sebaceous proliferations. Am J Dermatopathol 1986;8:202-208.

14 Davis DA, Cohen PR. Genitourinary tumors in men with the Muir-Torre syndrome. J Am Acad Dermatol 1995;33:909-912.

15 Lasser A, Carter DM. Multiple basal cell epitheliomas with sebaceous differentiation. Arch Dermatol 1973;107: 91-93.

16 McMullan FH. Sebaceous epithelioma. Arch Dermatol 1955;71:725-727.

17 Zackheim HS. The sebaceous epithelioma. Arch Dermatol 1964;89:711-724.

18 Okuda C, Ito $\mathrm{M}$, Fujiwara $\mathrm{H}$, et al. Sebaceous epithelioma with sweat gland differentiation. Am J Dermatopathol 1995;17:523-528.

19 Rothko F, Farmer ER, Zeligman I. Superficial epithelioma with sebaceous differentiation. Arch Dermatol 1980;116:329-331.

20 Friedman KJ, Boudreau S, Farmer ER. Superficial epithelioma with sebaceous differentiation. J Cutan Pathol 1987;14:193-197.

21 Lee MJ, Kim YC, Lew W. A case of superficial epithelioma with sebaceous differentiation. Yonsei Med J 2003;30:347-350.

22 Mahalingam M, Bhawan J, Finn R, et al. Tumor of the follicular infundibulum with sebaceous differentiation. J Cutan Pathol 2001;28:314-317.

23 Troy JL, Ackerman AB. Sebaceoma: a distinctive benign neoplasm of adnexal epithelium differentiating toward sebaceous cells. Am J Dermatopathol 1984;6:7-13.

24 Misago N, Mihara I, Ansai S-I, et al. Sebaceoma and related neoplasms with sebaceous differentiation. Am J Dermatopathol 2002;24:294-304.

25 Zaim MT. Sebocrine adenoma: an adnexal adenoma with sebaceous and apocrine poroma-like differentiation. Am J Dermatopathol 1988;10:311-318.

26 Grosshans E, Hanau D. L’adenome infundibulaire: un porome folliculaire a' differenciation sebacee et apocrine. Ann Dermatol Venereol 1981;108:59-66.

27 Misago N, Suse $\mathrm{T}$, Uemura $\mathrm{T}$, et al. Basal cell carcinoma with sebaceous differentiation. Am J Dermatopathol 2004;26:298-303.

28 Wick MR, Goellner JR, Wolfe III JT, et al. Adnexal carcinomas of the skin. II. Extraocular sebaceous carcinomas. Cancer 1985;56:1163-1172.

29 Wolfe III JT, Wick MR, Campbell RJ. Sebaceous carcinomas of the oculocutaneous adnexa and extraocular skin. In: Wick MR (ed). Pathology of Unusual Malignant Cutaneous Tumors. Marcel-Dekker: New York, 1985, pp 77-106.
30 Wolfe III JT, Campbell RJ, Yeatts RP, et al. Sebaceous carcinoma of the eyelid: errors in clinical and pathologic diagnosis. Am J Surg Pathol 1984;8: 597-606.

31 Rao NA, Hidayat AA, McLean IW, et al. Sebaceous carcinoma of the ocular adnexa: a clinicopathologic study of 104 cases, with five-year followup data. Hum Pathol 1982;13:113-122.

$32 \mathrm{Ni} \mathrm{C,} \mathrm{Kuo} \mathrm{PK.} \mathrm{Meibomian} \mathrm{gland} \mathrm{carcinoma:} \mathrm{a}$ clinicopathological study of 156 cases with longperiod followup of 100 cases. Jpn J Ophthalmol 1979;23:388-401

33 Graham RM, McKee PH, McGibbon D. Sebaceous carcinoma. Clin Exp Dermatol 1984;9:466-471.

34 Doxanas MT, Green WR. Sebaceous gland carcinoma: review of 40 cases. Arch Ophthalmol 1984;102: $245-249$.

35 Ausidio RA, Lodeville O, Quaglivolo V, et al. Sebaceous carcinoma arising from the eyelid and from extraocular sites. Tumori 1987;73:531-535.

36 Nguyen GK, Mielke BW. Extraocular sebaceous carcinoma with intraepidermal (pagetoid) spread. Am J Dermatopathol 1987;9:304-305.

37 Nelson BR, Hamlet KR, Gillard M, et al. Sebaceous carcinoma. J Am Acad Dermatol 1995;33:1-15.

38 Harvey PA, Parsons MA, Rennie IG. Primary sebaceous carcinoma of lacrimal gland: a previously unreported primary neoplasm. Eye 1994;8: 592-595.

39 Ansai S, Hashimoto H, Aoki T, et al. A histochemical and immunohistochemical study of extraocular sebaceous carcinoma. Histopathology 1993;22:127-133.

40 Shields JA, Demirci H, Marr BP, et al. Sebaceous carcinoma of the eyelids: personal experience with 60 cases. Ophthalmology 2004;111:2151-2157.

41 Oppenheim AR. Sebaceous carcinoma of the penis. Arch Dermatol 1981;117:306-307.

42 Bassetto F, Baraziol R, Sottosanti MV, et al. Biological behaviour of the sebaceous carcinoma of the head. Dermatol Surg 2004;30:472-476.

43 Cohen PR, Kohn SR. Association of sebaceous gland tumors and internal malignancy: the Muir-Torre syndrome. Am J Med 1991;90:606-613.

44 Moreno C, Jacyk WK, Judd MJ, et al. Highly aggressive extraocular sebaceous carcinoma. Am J Dermatopathol 2001;23:450-455.

45 Ohara M, Sotozono C, Tsuchihashi Y, et al. Ki-67 labeling index as a marker of malignancy in ocular surface neoplasms. Jpn J Ophthalmol 2004;48:524529.

46 Luderschmidt C, Plewig G. Circumscribed sebaceous gland hyperplasia: autoradiographic and histoplanometric studies. J Invest Dermatol 1978;70:207-209.

47 Kudoh K, Hosokawa M, Miyazawa T, et al. Giant solitary sebaceous gland hyperplasia clinically simulating epidermoid cyst. J Cutan Pathol 1988;15: 396-398.

48 Nakamura SI, Nakayama K, Nishihara K, et al. Sebaceous carcinoma, with special reference to the histopathologic differential diagnosis. J Dermatol 1988;15:55-59.

49 Misago N, Narisawa Y. Sebaceous carcinoma with apocrine differentiation. Am J Dermatopathol 2001; 23:50-57.

50 Kazakov DV, Kutzner H, Rutten A, et al. Carcinoidlike pattern in sebaceous neoplasms: another distinctive, previously unrecognized pattern in extra- 
ocular sebaceous carcinoma and sebaceoma. Am J Dermatopathol 2005;27:195-203.

51 Abbott JJ, Hernandez-Rios P, Amirkhan RH, et al. Cystic sebaceous neoplasms in Muir-Torre syndrome. Arch Pathol Lab Med 2003;127:614-617.

52 Sinard JH. Immunohistochemical distinction of ocular sebaceous carcinoma from basal cell and squamous carcinoma. Arch Ophthalmol 1999;117: 776-783.

53 Ansai S, Mitsuhashi Y, Kondo S, et al. Immunohistochemical differentiation of extra-ocular sebaceous carcinoma from other skin cancers. J Dermatol 2004;31:998-1008.

54 Hassanein AM. Sebaceous carcinoma and the Tantigen. Semin Cutan Med Surg 2004;23:62-72.

55 Rishi K, Font RL. Sebaceous gland tumors of the eyelids and the conjunctiva in the Muir-Torres syndrome: a clinicopathological study of five cases and literature review. Ophthal Plast Reconstr Surg 2004;20:31-36.

56 Swanson PE, Wick MR. Immunohistochemistry of cutaneous tumors. In: Leong ASY (ed). Applied Immunohistochemistry for the Surgical Pathologist. Edward Arnold: London, 1993, pp 269-308.

57 Crowson AN, MacInnes C, Carlson-Sweet $\mathrm{K}$, et al. Clear cell atypical fibroxanthoma: a clinicopathological study. J Cutan Pathol 2002;29:374-381.

58 Crowson AN, Taylor JR, Magro CM. Clear cell vs 'conventional' atypical fibroxanthoma: a clinicopathologic study of 10 cases. Lab Invest 2003;90A.

59 Jensen K, Wilkinson B, Wines N, et al. Procollagen 1 expression in atypical fibroxanthoma and other tumors. J Cutan Pathol 2004;31:57-61.

60 McBride SR, Leonard N, Reynolds NJ. Loss of p21 (WAF1) compartmentalisation in sebaceous carcinoma compared with sebaceous hyerplasia and sebaceous adenoma. J Cutan Pathol 2002;55: $763-766$.

61 Jimenez FJ, Burchette Jr JL, Grichnik JM, et al. BEREP4 immunoreactivity in normal skin and cutaneous neoplasms. Mod Pathol 1995;8:854-858.

62 Mehregan AH, Pinkus H. Life history of organoid nevi: special reference to nevus sebaceus of Jadassohn. Arch Dermatol 1965;91:574-587.

63 Morioka S. The natural history of nevus sebaceus. J Cutan Pathol 1985;12:200-213.

64 Lentz CL, Altman J, Mopper C. Nevus sebaceus of Jadassohn. Arch Dermatol 1968;97:294-296.

65 Wilson-Jones E, Heyl T. Nevus sebaceus: a report of 140 cases with special regard to the development of secondary malignant tumors. Br J Dermatol 1970;82: 99-105.

66 Clancy RR, Kurtz MB, Baker D, et al. Neurologic manifestations of the organoid nevus syndrome. Arch Neurol 1985;42:236-240.

67 Zaremba J. Jadassohn's nevus phakomatosis: a study based on a review of 37 cases. J Ment Defic Res 1977;22:103-122.

68 Alessi E, Wong SN, Advani HH, et al. Nevus sebaceus is associated with unusual neoplasms: an atlas. Am J Dermatopathol 1988;10:116-127.

69 Crowson AN, Magro CM. Desmoplastic trichilemmoma and its association with basal cell carcinoma. Am J Dermatopathol 1996;18:43-48.

$70 \mathrm{Ng}$ WK. Nevus sebaceus with apocrine and sebaceous differentiation. Am J Dermatopathol 1996;18: 420-423.
71 Crowson AN, Magro CM, Kadin M, et al. Differential expression of bcl-2 oncogene in human basal cell carcinoma. Hum Pathol 1996;27:355-359.

72 Domingo J, Helwig EB. Malignant neoplasms associated with nevus sebaceus of Jadassohn. J Am Acad Dermatol 1979;1:545-556.

73 Tarkhan H, Domingo J. Metastasizing eccrine porocarcinoma developing in a nevus sebaceus of Jadassohn: report of a case. Arch Dermatol 1985; 121:413-415.

74 Headington JT. Tumors of the hair follicle: a review. Am J Pathol 1976;85:480-505.

75 Ten Seldam REJ. Tricholemmocarcinoma. Australas J Dermatol 1977;18:62-72.

76 Krumrey KW. The tricholemmal carcinoma: report of a case with review of the literature. Aktuel Dermatol 1984;10:70-72.

77 Schell H, Haneke E. Tricholemmal carcinoma: report of 11 cases. Hautarzt 1986;37:384-387.

78 Grouls V. Tricholemmale Keratose und tricholemmales Karzinom. Hautarzt 1987;38:335-341.

79 Boscaino A, Terracciano LM, Donofrio V, et al. Trichilemmal carcinoma: a study of seven cases. J Cutan Pathol 1992;19:94-99.

80 Swanson PE, Marrogi AJ, Williams DJ, et al. Trichilemmal carcinoma. J Cutan Pathol 1992;19:100-109.

81 Reis JP, Tellechea O, Cunha MF, et al. Trichilemmal carcinoma: review of eight cases. J Cutan Pathol 1993;20:44-49.

82 Wong TY, Suster S. Trichilemmal carcinoma: a clinicopathologic study of 13 cases. Am J Dermatopathol 1994;16:463-473.

83 Garrett AB, Azmi FH, Ogburia KS. Trichilemmal carcinoma: a rare cutaneous malignancy: a report of two cases. Dermatol Surg 2004;30:113-115.

84 Lai TF, Huilgol SC, James CL, et al. Trichilemmal carcinoma of the upper eyelid. Acta Ophthalmol Scand 2003;81:536-538.

85 Allee JE, Cotsarelis G, Solky B, et al. Multiple recurrent trichilemmal carcinoma with perineural invasion and cytokeratin 17 positivity. Dermatol Surg 2003;29:886-889.

86 Ohnishi T, Watanabe S. Immunohistochemical analysis of cytokeratin expression in various trichogenic tumors. Am J Dermatopathol 1999;21:337-343.

87 Haas N, Audring H, Sterry W. Carcinoma arising in a proliferating trichilemmal cyst expresses fetal and trichilemmal hair phenotype. Am J Dermatopathol 2002;24:340-344.

88 Mori O, Hachisuka H, Sasai Y. Proliferating trichilemmal cyst with spindle cell carcinoma. Am J Dermatopathol 1990;12:479-484.

89 Alvarez-Quinones M, Garijo MF, Fernandez F, et al. Malignant aneuploid spindle cell transformation in a proliferating trichilemmal tumor. Acta Dermatol Venereol 1993;73:444-446.

90 Marrogi AJ, Wick MR, Dehner LP. Pilomatrical neoplasms in children and young adults. Am J Dermatopathol 1992;14:87-94.

91 Kaddu S, Soyer HP, Hodl S, et al. Morphological stages of pilomatricoma. Am J Dermatopathol 1996;18:333-338.

92 Ter Poorten HJ, Sharbaugh AH. Extruding pilomatricoma: report of a case. Cutis 1978;22:47-49.

93 Tsoitis G, Mandinaos C, Kanitakis JC. Perforating calcifying epithelioma of Malherbe with a rapid evolution. Dermatologica 1984;168:233-237. 
94 Zulaica A, Peteiro C, Quintas C, et al. Perforating pilomatricoma. J Cutan Pathol 1988;15:409-411.

95 Alli N, Gungor E, Artuz F. Perforating pilomatricoma. J Am Acad Dermatol 1996;35:116-118.

96 Lee WS, Yoo MS, Ahn SK. Anetodermic cutaneous changes overlying pilomatricoma. Int J Dermatol 1995;34:144-145.

97 Shames BS, Nassif A, Bailey CS, et al. Secondary anetoderma involving a pilomatricoma. Am J Dermatopathol 1994;16:557-560.

98 Forbis R, Helwig EB. Pilomatrixoma (calcifying epithelioma). Arch Dermatol 1961;83:606-618.

99 Moehlenbeck FW. Pilomatrixoma (calcifying epithelioma). Arch Dermatol 1973;108:532-534.

100 Taaffe A, Wyatt EH, Bury HPR. Pilomatrixoma (Malherbe). A clinical and histological survey of 78 cases. Int J Dermatol 1988;27:477-480.

101 Kaddu S, Soyer HP, Cerroni L, et al. Clinical and histopathological spectrum of pilomatricoma in adults. Int J Dermatol 1994;33:705-708.

102 Bassarova A, Nesland JM, Sebloev T, et al. Pilomatrix carcinoma with lymph node metastases. J Cutan Pathol 2004;31:330-335.

103 Inglefield CJ, Muir IF, Gray ES. Aggressive pilomatricoma in childhood. Ann Plast Surg 1994;33: 656-658.

104 Lopansri S, Mihm MC. Pilomatrix carcinoma or calcifying epitheliocarcinoma of Malherbe: a case report and review of the literature. Cancer 1980;45: 2368-2373.

105 Gray M, Parhizgar B, Beerman H. Malignant pilomatrixoma. Arch Dermatol 1984;120:770-773.

106 Manivel JC, Wick MR, Mukai K. Pilomatrix carcinoma: an immunohistochemical comparison with benign pilomatrixoma and other benign lesions of pilar origin. J Cutan Pathol 1986;13:22-29.

107 Gould E, Kurzon R, Kowalczyk AP, et al. Pilomatrix carcinoma with pulmonary metastases: a report of a case. Cancer 1984;54:370-372.

108 Van der Walt JD, Rohlova B. Carcinomatous transformation in a pilomatrixoma. Am J Dermatopathol 1984;6:63-69.

109 Weedon D, Bell J, Maize J. Matrical carcinoma of the skin. J Cutan Pathol 1980;7:39-42.

110 Reed RJ, Lamar LM. Invasive hair matrix tumors of the scalp: invasive pilomatrixoma. Arch Dermatol 1966;94:310-316.

111 Martelli G, Giardini R. Pilomatrix carcinoma: a case report and review of the literature. Eur J Surg Oncol 1994;20:703-704.

112 Panico L, Manivel JC, Pettinato G, et al. Pilomatrix carcinoma. Tumori 1994;80:309-314.

113 Sau P, Lupton GP, Graham JH. Pilomatrix carcinoma. Cancer 1993;71:2491-2498.

114 Zagarella SS, Kneale KL, Stern HS. Pilomatrix carcinoma of the scalp. Aust J Dermatol 1992;33: 39-42.

115 Niedermeyer HP, Peris K, Hofler H. Pilomatrix carcinoma with multiple visceral metastases: report of a case. Cancer 1996;77:1311-1314.

116 Rahbari H, Mehregan AH. Pilary complex carcinoma: an adnexal carcinoma of the skin with differentiation towards the components of the pilary complex. J Dermatol 1993;20:630-637.

117 Sanchez-Yus E, Requena L, Simon P, et al. Complex adnexal tumor of the primary epithelial germ with distinct patterns of superficial epithelioma with sebaceous differentiation, immature trichoepithelioma, and apocrine adenocarcinoma. Am J Dermatopathol 1992;14:245-252.

118 Wick MR, Swanson PE, LeBoit PE, et al. Lymphoepithelioma-like carcinomas of the skin with adnexal differentiation. J Cutan Pathol 1991;18:93-102.

119 Requena L, Sanchez-Yus E, Jimenez E, et al. Lymphoepithelioma-like carcinoma of the skin: a light microscopic and immunohistochemical study. J Cutan Pathol 1994;21:541-548.

120 Barr RJ, Goodman MM. Neurofollicular hamartoma. A light microscopic and immunohistochemical study. J Cutan Pathol 1989;16:336-341.

121 Nova MP, Zung M, Halperin A. Neurofollicular hamartoma. A clinicopathological study. Am J Dermatopathol 1991;13:459-462.

122 Sangueza OP, Requena L. Neurofollicular hamartoma. A new histogenetic interpretation. Am J Dermatopathol 1994;16:150-154.

123 Tuthill RJ, Clark Jr WH, Levene A. Pilar neurocristic hamartoma: its relationship to blue nevus and equine melanotic disease. Arch Dermatol 1982;118:592-596.

124 Crowson AN, Magro CM, Clark WHC. Pilar neurocristic hamartoma (letter). J Am Acad Dermatol 1996; 34:715.

125 Pathy AL, Helm TN, Elston D, et al. Malignant melanoma arising in a blue nevus with features of pilar neurocristic hamartoma. J Cutan Pathol 1993;20: 459-464.

126 Pearson JP, Weiss SW, Headington JT. Cutaneous malignant melanotic neurocristic tumors arising in neurocristic hamartomas: a melanocytic tumor morphologically and biologically distinct from common melanoma. Am J Surg Pathol 1996;20:665-677.

127 Page DL, Anderson TJ, Sakamoto G. Infiltrating carcinoma: major histological types. In: Page DL, Anderson TJ (eds). Diagnostic Histopathology of the Breast. Churchill-Livingstone: New York, 1987, pp 193-295.

128 Busam KJ, Tan LK, Granter SR, et al. Epidermal growth factor, estrogen, and progesterone receptor expression in primary sweat gland carcinomas and primary and metastatic mammary carcinomas. Mod Pathol 1999;12:786-793.

129 Hiatt KM, Pilow JL, Smoller BR. Her-2 expression in cutaneous eccrine and apocrine neoplasms. Mod Pathol 2004;17:28-32.

130 Qureshi HS, Ormsby AH, Lee MW, et al. The diagnostic utility of p63, CK5/6, CK 7, and Ck 20 in distinguishing primary cutaneous adnexal neoplasms from metastatic carcinomas. Cutan Pathol 2004;31: 145-152.

131 Plumb SJ, Argenyi ZB, Stone MS, et al. Cytokeratin 5/ 6 immunostaining in cutaneous adnexal neoplasms and metastatic adenocarcinoma. Am J Dermatopathol 2004;26:447-451.

132 Ivan D, Hafeez Diwan A, Prieto VG. Expression of p63 in primary cutaneous adnexal neoplasms and adenocarcinoma metastatic to the skin. Mod Pathol 2005;18:137-142.

133 Goedde TA, Bumpers H, Fiscella J, et al. Eccrine porocarcinoma. J Surg Oncol 1994;55:261-264.

134 Poiares-Baptista A, Tellechea O, Reis JP, et al. Eccrine porocarcinoma: a review of 24 cases. Ann Dermatol Venereol 1993;120:107-115.

135 Snow SN, Reizner GT. Eccrine porocarcinoma of the face. J Am Acad Dermatol 1992;27:306-311. 
136 Yamamoto O, Haratake J, Yokoyama S, et al. A histopathological and ultrastructural study of eccrine porocarcinoma with special reference to its subtypes. Virchows Arch A Pathol Anat Histopathol 1992; 420:395-401.

137 Turner JJ, Maxwell L, Bursle CA. Eccrine porocarcinoma. Pathology 1982;14:469-475.

138 Shaw M, McKee PH, Lowe D, et al. Malignant eccrine poroma: a study of twenty seven cases. Br J Dermatol 1982;107:675-680.

139 Bottles K, Sagebiel RW, McNutt NS, et al. Malignant eccrine poroma. Cancer 1984;53:1579-1585.

140 Ryan JF, Darley CR, Pollock DJ. Malignant eccrine poroma: report of three cases. J Clin Pathol 1986; 39:1099-1104.

141 Mehregan AH, Hashimoto K, Rahbari H. Eccrine adenocarcinoma: a clinicopathologic study of 35 cases. Arch Dermatol 1983;119:104-114.

142 Akalin T, Sen S, Yuceturk A, et al. p53 protein expression in eccrine poroma and porocarcinoma. Am J Dermatopathol 2001;23:402-406.

143 Wick MR, Swanson PE, Barnhill RL. Sweat gland tumors. In: Barnhill RL, Crowson AN (eds). Textbook of Dermatopathology, 2nd edn. McGraw-Hill Co.: New York, 2004, pp 745-784.

144 Miyashita M, Suzuki H. In situ porocarcinoma: a case with malignant expression in clear tumor cells. Int J Dermatol 1993;32:749-750.

145 Bardach H. Hidroacanthoma simplex with in situ porocarcinoma. J Cutan Pathol 1978;5:236-248.

146 Isikawa K. Malignant hidroacanthoma simplex. Arch Dermatol 1972;104:529-532.

147 Moreno R, Salvatella N, Guix M, et al. Malignant hidroacanthoma simplex. Dermatologica 1984;169: 318-322.

148 Manteaux A, Cohen PR, Rapini RP. Zosteriform and epidermotropic metastasis: report of two cases. J Dermatol Surg Oncol 1992;18:97-100.

149 Hara K, Kamiya S. Pigmented eccrine porocarcinoma: a mimic of malignant melanoma. Histopathology 1995;27:86-88.

150 Wick MR, Swanson PE. Cutaneous Adnexal Tumors: A Guide to Pathologic Diagnosis. ASCP Press: Chicago, 1991

151 Hashimoto K, Mehregen AH, Kumakiri M. Tumors of Skin Appendages. Butterworths: Boston, 1987, pp 48-51.

152 Van der Putte SC. The pathogenesis of familial multiple cylindromas, trichoepitheliomas, milia, and spiradenomas. Am J Dermatopathol 1995;17: 271-280.

153 Cooper PH. Carcinomas of sweat glands. Pathol Annu 1987;22(Part 1):83-124.

154 Ohta M, Hiramoto M, Fujii M, et al. Nodular hidradenocarcinoma on the scalp of a young woman: case report and review of literature. Dermatol Surg 2004;30:1265-1268.

155 Fukamizu H, Tomita K, Inoue K, et al. Primary mucinous carcinoma of the skin. J Dermatol Surg Oncol 1993;19:625-628.

156 Ghamande SA, Kasznick J, Griffiths CT, et al. Mucinous adenocarcinomas of the vulva. Gynecol Oncol 1995;57:117-120.

157 Katoh N, Hirano S, Hosokawa Y, et al. Mucinous carcinoma of the skin: report of a case with DNA cytofluorometric study. J Dermatol 1994;21: 117-121.
158 Mendoza S, Helwig EB. Mucinous (adenocystic) carcinoma of the skin. Arch Dermatol 1971;103: $68-78$.

159 Rodriguez MM, Lubowitz RM, Shannon GM. Mucinous (adenocystic) carcinoma of the eyelid. Arch Ophthalmol 1973;89:493-494.

160 Grossman JR, Izuno GT. Primary mucinous (adenocystic) carcinoma of the skin. Arch Dermatol 1974;110:274-276.

161 Santa Cruz DJ, Meyers JH, Gnepp DR, et al. Primary mucinous carcinoma of the skin. $\mathrm{Br} \mathrm{J}$ Dermatol 1978;68:645-653.

162 Yeung KY, Stinson JC. Mucinous (adenocystic) carcinoma of sweat glands with widespread metastasis. Cancer 1977;39:2556-2562.

163 Pilgram JP, Kloss SG, Wolfish PS, et al. Primary mucinous carcinoma of the skin with metastases to the lymph nodes. Am J Dermatopathol 1985;7: 461-469.

164 Rahilly MA, Beattie GJ, Lessells AM. Mucinous eccrine carcinoma of the vulva with neuroendocrine differentiation. Histopathology 1995;27:82-86.

165 Minami Y, Uede K, Sagawa K, et al. Immunohistochemical staining of cutaneous tumours with G-81, a monoclonal antibody to dermcidin. Br J Dermatol 2004;141:165-169.

166 Rosen T. Cutaneous metastases. Med Clin North Am 1980;64:885-900.

167 Koh BK, Choi JM, Yi JY, et al. Recurrent primary cutaneous adenoid cystic carcinoma of the scrotum. Int J Dermatol 2001;40:724-725.

168 Chu SS, Chang YL, Lou PJ. Primary cutaneous adenoid cystic carcinoma with regional lymph node metastasis. J Laryngol Otol 2001;115:673-675.

169 Urso C, Bondi R, Paglierani M, et al. Carcinomas of sweat glands: report of 60 cases. Arch Pathol Lab Med 2001;125:498-505

170 Chang SE, Ahn SJ, Choi JH, et al. Primary adenoid cystic carcinoma of skin with lung metastasis. J Am Acad Dermatol 1999;40:640-642.

171 DeLucia A, Gambardella T, Carra P, et al. A case of highly aggressive adenoid cystic carcinoma of the external auditory canal. Acta Otorhinolaryngol Ital 2004;24:354-356.

172 Wassef M, Thomas V, Deffrennes D, et al. Primary adenoid cystic carcinoma of the skin: histologic and ultrastructural study of two cases localized in the external auditory canal. Ann Pathol 1995;15:150-155.

173 Eckert F, Pfau A, Landthaler M. Adenoid cystic sweat gland carcinoma: a clinicopathologic and immunohistochemical study. Hautarzt 1994;45:318-323.

174 Matsumura T, Kumakiri M, Ohkaware A, et al. Adenoid cystic carcinoma of the skin: an immunohistochemical and ultrastructural study. J Dermatol 1993;20:164-170.

175 Cooper PH, Adelson GL, Holthaus WH. Primary cutaneous adenoid cystic carcinoma. Arch Dermatol 1984;120:774-777.

176 Wick MR, Swanson PE. Primary adenoid cystic carcinoma of the skin. Am J Dermatopathol 1986; $8: 2-13$.

177 Seab JA, Graham JH. Primary cutaneous adenoid cystic carcinoma. J Am Acad Dermatol 1987;17: 113-118.

178 Van der Kwast TH, Vuzevski VD, Ramaekers F. Primary cutaneous adenoid cystic carcinoma. Br J Dermatol 1988;118:567-576. 
179 Dardick I, van Nostrand AW, Phillips MJ. Histogenesis of salivary gland pleomorphic adenoma (mixed tumor) with evaluation of the role of myoepithelial cells. Hum Pathol 1982;13:62-75.

180 Inaloz HS, Patel GK, Knight AG. An aggressive treatment for aggressive digital papillary adenocarcinoma. Cutis 2002;69:179-182; quiz 210.

181 Smith KJ, Skelton HG, Holland TT. Recent advances and controversies concerning adnexal neoplasms. Dermatol Clin 1992;10:117-160.

182 Goldstein DJ, Barr RJ, Santa Cruz DJ. Microcystic adnexal carcinoma: a distinct clinicopathologic entity. Cancer 1982;50:566-572.

183 Kao GF, Graham JH, Helwig EB. Aggressive digital papillary adenoma and adenocarcinoma (abstract). Arch Dermatol 1984;120:1612.

184 Rulon DB, Helwig EB. Papillary eccrine adenoma. Arch Dermatol 1977;113:596-598.

185 Elpern DJ, Farmer ER. Papillary eccrine adenoma. Arch Dermatol 1978;114:1241.

186 Cooper PH, Frierson HF. Papillary eccrine adenoma. Arch Pathol Lab Med 1984;108:55-57.

187 Urmacher C, Lieberman PH. Papillary eccrine adenoma: a light microscopic and immunohistochemical study. Am J Dermatopathol 1987;9:243-249.

188 Falck VG, Jordaan HF. Papillary eccrine adenoma. A tubulopapillary hidradenoma with eccrine differentiation. Am J Dermatopathol 1986;8:64-72.

189 Swanson PE, Cherwitz DL, Neumann MP, et al. Eccrine sweat gland carcinoma: an histologic and immunohistochemical study of 32 cases. J Cutan Pathol 1987;14:65-86.

190 Sexton M, Maize JC. Papillary eccrine adenoma: a light microscopic and immunohistochemical study. J Am Acad Dermatol 1988;18:1114-1120.

191 Kanitakis J, Hermier C, Thivolet J. Papillary eccrine adenoma. Am J Dermatopathol 1988;10: 180-182.

192 Jerasutus S, Suvanprakorn P, Wongchinchai M. Papillary eccrine adenoma: an electron microscopic study. J Am Acad Dermatol 1989;20:1111-1114.

193 Hashimoto K, Kato I, Taniguchi Y, et al. Papillary eccrine adenoma. Immunohistochemical and ultrastructural analyses. J Dermatol Sci 1990;1:65-71.

194 Requena L, Pena M, Sanchez M, et al. Papillary eccrine adenoma-a light-microscopic and immunohistochemical study. Clin Exp Dermatol 1990;15: 425-428.

195 Aloi F, Pich A. Papillary eccrine adenoma: a histopathological and immunohistochemical study. Dermatologica 1991;182:47-51.

196 Fox SB, Cotton DW. Tubular apocrine adenoma and papillary eccrine adenoma. Entities or unity? Am J Dermatopathol 1992;14:149-154.

197 Lever WF. Schaumberg-Lever. Histopathology of the Skin, 7th edn. JB Lippincott \& Co.: Philadelphia, 1989, pp 638-639.

198 Galadari E, Mehregan AH, Lee KC. Malignant transformation of eccrine tumors. J Cutan Pathol 1987; 14:15-22.

199 Duke WH, Sherrod TT, Lupton GP. Aggressive digital papillary adenocarcinoma (aggressive digital papillary adenoma and adenocarcinoma revisited). Am J Surg Pathol 2000;24:775-784.

200 Kao GF, Helwig EG, Graham JH. Aggressive digital papillary adenoma and adenocarcinoma. A clinicopathological study of 57 patients, with histochemical, immunopathological, and ultrastructural observations. J Cutan Pathol 1987;14:129-146.

201 Guccion JG, Patterson RH, Nayar R, et al. Papillary eccrine adenoma: an ultrastructural and immunohistochemical study. Ultrastruct Pathol 1998;22:263269.

202 Ichikawa E, Okabe S, Umebayashi Y, et al. Papillary eccrine adenoma: immunohistochemical studies of keratin expression. J Cutan Pathol 1997;24:564-570.

203 Elder DE, Elenitsas R, Ragsdale B. Tumors of the epidermal appendages. In: Elder DE, Johnson BE, Jaworsky C, Elenitsas R (eds). Lever's Histopathology of the Skin, 8th edn. JB Lippincott Co.: Philadelphia, 1997, pp 747-803.

204 Malafa MP, McKesey P, Stone S, et al. Sentinel node biopsy for aggressive digital papillary adenocarcinoma. Dermatol Surg 2000;26:580-583.

205 Daigeler A, Fansa H, Tammer M, et al. Aggressive digital papillary adenocarcinoma-a case report. Handchir Mikrochir Plast Chir 2002;34:137-139.

206 Wick MR, Cooper PH, Swanson PE, et al. Microcystic adnexal carcinoma: an immunohistochemical comparison with other cutaneous appendage tumors. Arch Dermatol 1990;126:189-194.

207 Nickoloff BJ, Fleischmann HE, Carmel J. Microcystic adnexal carcinoma: immunohistologic observations suggesting dual (pilar and eccrine) differentiation. Arch Dermatol 1986;122:290-294.

208 Callahan EF, Vidimos AT, Bergfeld WF. Microcystic adnexal carcinoma (MAC) of the scalp with extensive pilar differentiation. Dermatol Surg 2002;28:536-539.

209 Ongenae KC, Verhaegh ME, Vermeulen $\mathrm{AH}$, et al. Microcystic adnexal carcinoma: an uncommon tumor with debatable origin. Dermatol Surg 2001;27: 979-984.

210 Ohtsuka H, Nagamatsu S. Microcystic adnexal carcinoma: review of 51 Japanese patients. Dermatology 2002;204:190-193.

211 Snow S, Madjar DD, Hardy S, et al. Microcystic adnexal carcinoma: report of 13 cases and review of the literature. Dermatol Surg 2001;27:401-408.

212 Chiller K, Passaro D, Scheuller M, et al. Microcystic adnexal carcinoma: forty-eight cases, their treatment, and their outcome. Arch Dermatol 2000;136:13551359.

213 Carroll P, Goldstein GD, Brown Jr CW. Metastatic microcystic adnexal carcinoma in an immunocompromised patient. Dermatol Surg 2000;26:531-534.

214 Friedman PM, Friedman RH, Jiang SB, et al. Microcystic adnexal carcinoma: collaborative series review and update. J Am Acad Dermatol 1999;41:225-231.

215 Beer KT, Buhler SS, Mullis P, et al. A microcystic adnexal carcinoma in the auditory canal 15 years after radiotherapy of a 12-year-old boy with nasopharynx carcinoma. Strahlender Onkol 2005;181: 405-410.

216 Ohtsuka H, Nozawa R, Kushida Y. Synchronous microcystic adnexal carcinoma and gastric cancer with review of the literature. J Dermatol 2005;32: 43-47.

217 Kachemoune A, Olbricht SM, Johnson DS. Microcytstic adnexal carcinoma: report of four cases treated with Mohs' micrographic surgical technique. Int J Dermatol 2005;44:507-512.

218 Cooper PH, Mills SE, Leonard DD, et al. Sclerosing sweat duct (syringomatous) carcinoma. Am J Surg Pathol 1985;9:422-433. 
219 Cooper PH. Sclerosing carcinomas of sweat ducts (microcystic adnexal carcinoma). Arch Dermatol 1986;122:261-264.

220 Berg JW, McDivitt RW. Pathology of sweat gland carcinomas. Pathol Annu 1968;3:123-144.

221 Lipper S, Peiper SC. Sweat gland carcinoma with syringomatous features. Cancer 1979;44:157-163.

222 Cooper PH, Mills SE. Microcystic adnexal carcinoma. J Am Acad Dermatol 1984;10:908-914.

223 McAlvany JP, Stonecipher MR, Leshin B, et al. Sclerosing sweat duct carcinoma in an 11 year old boy. J Dermatol Surg Oncol 1994;20:767-768.

224 Batsakis JG, El-Naggar AK, Weber RS. Two perplexing skin tumors: microcystic adnexal carcinoma and keratoacanthoma. Ann Otol Rhinol Laryngol 1994; 103:829-832.

225 LeBoit PE, Sexton M. Microcystic adnexal carcinoma of the skin. A reappraisal of the differentiation and differential diagnosis of an underrecognized neoplasm. J Am Acad Dermatol 1993;29:609-618.

226 Hesse RJ, Scharfenberg JC, Ratz JL, et al. Eyelid microcystic adnexal carcinoma. Arch Ophthalmol 1995;113:494-496.

227 Verdier-Sevrain S, Thomine E, Lauret $\mathrm{P}$, et al. Syringomatous carcinoma: apropos of three cases with a review of the literature. Ann Pathol 1995;15: 280-284.

228 Schlipper JH, Holecek BU, Sievers KW. A tumor derived from Ebner's glands: microcystic adnexal carcinoma of the tongue. J Laryngol Otol 1995;109: 1211-1214.

229 Yus ES, Caballero LR, Salazar IG, et al. Clear cell syringoid eccrine carcinoma. Am J Dermatopathol 1987;9:225-231.

230 Smith KJ, Williams J, Corbett D, et al. Microcystic adnexal carcinoma: an immunohistochemical study including markers of proliferation and apoptosis. Am J Surg Pathol 2001;25:464-471.

231 Pruzam DL, Esterly NB, Prose NS. Eruptive syringoma. Arch Dermatol 1989;125:1119-1120.

232 Brownstein MH, Shapiro L. Desmoplastic trichoepithelioma. Cancer 1977;40:2979-2986.

233 Salasche SJ, Amonette RA. Morpheaform basal cell epitheliomas. J Dermatol Surg Oncol 1981;7: 387-394.

234 Smith KJ, Skelton HG. Familial syringomas: an example of gonadal mosaicism. Cutis 2001;68: 293-295.

235 Draznin M. Hereditary syringomas: a case report. Dermatol Online J 2004;115:19.

236 Biernat W, Jablkowski W. Syringomatous adenoma of the nipple. Pol J Pathol 2000;51:201-202.

237 Banks ER, Cooper PH. Adenosquamous carcinoma of the skin: a report of 10 cases. J Cutan Pathol 1991;18:227-234.

238 Weidner N, Foucar E. Adenosquamous carcinoma of the skin: an aggressive mucin- and gland-forming squamous carcinoma. Arch Dermatol 1985;121: 775-779.

239 Sakamoto F, Ito M, Oguro K, et al. Adenosquamous carcinoma of the skin: ultrastructural and immunohistochemical studies. Jpn J Dermatol 1990;100: 1183-1190.

240 Azorin D, Lopez-Rios F, Ballestin C, et al. Primary cutaneous adenosquamous carcinoma: a case report and review of the literature. J Cutan Pathol 2001;28:542-545.
241 Landman G, Farmer ER. Primary cutaneous mucoepidermoid carcinoma: report of a case. J Cutan Pathol 1991;18:56-59.

242 Wenig BL, Sciubba JJ, Goodman RS, et al. Primary cutaneous mucoepidermoid carcinoma of the anterior neck. Laryngoscope 1983;93:464-467.

243 Friedman KJ. Low-grade primary cutaneous adenosquamous (mucoepidermoid) carcinoma. Am J Dermatopathol 1989;11:43-50.

244 Smoller BR, Narurkar V. Mucoepidermoid carcinoma metastatic to the skin: an histologic mimic of a primary sweat gland carcinoma. J Dermatol Surg Oncol 1992;18:365-368.

245 Metcalf JS, Maize JC, Shaw EB. Bronchial mucoepidermoid carcinoma metastatic to skin: report of a case and review of the literature. Cancer 1986;58:25562559.

246 Barsky SH, Martin SE, Matthews M, et al. 'Low grade' mucoepidermoid carcinoma of the bronchus with 'high grade' biological behavior. Cancer 1983;51: 1505-1509.

247 Revercomb CH, Reitmeyer WJ, Pulitzer DR. Clear cell variant of mucoepidermoid carcinoma of the skin. J Am Acad Dermatol 1993;29:642-644.

248 Diwan AH, Smith KJ, Brown R, et al. Mucoepidermoid carcinoma arising within nevus sebaceus of Jadassohn. J Cutan Pathol 2003;30:652-655.

249 Wildemore JK, Lee JB, Humphreys TR. Mohs surgery for malignant eccrine neoplasms. Dermatol Surg 2004;30:1574-1579.

250 Fernandez-Figueras MT, Fuente MJ, Bielsa I, et al. Low-grade mucoepidermoid carcinoma on the vermilion border of the lip. Am J Dermatopathol 1997; 19:197-201.

251 Harris TJ, Jine JD, Berman RS, et al. Neutrophilic eccrine hidradenitis. A distinctive type of neutrophilic dermatosis associated with myelogenous leukemia and chemotherapy. Arch Dermatol 1982;118:263-266.

252 Riedlinger WF, Hurley MY, Dehner LP, et al. Mucoepidermoid carcinoma of the skin: a distinct entity from adenosquamous carcinoma: a case study with a review of the literature. Am J Surg Pathol 2005; 29:131-135.

253 Bondeson L. Malignant dermal eccrine cylindroma. Acta Dermatol Venereol 1979;59:92-94.

254 Boulond A, Clerens A, Signard H. Cylindrome malin. Dermatologica 1979;158:203-207.

255 Urbanski SJ, From L, Abramowicz A. Metamorphosis of dermal cylindroma: possible relation to malignant transformation. J Am Acad Dermatol 1985;12: 188-195.

256 Rockerbie N, Solomon AR, Woo TY, et al. Malignant dermal cylindroma in a patient with multiple dermal cylindromas, trichoepitheliomas, and bilateral dermal analogue tumors of the parotid gland. Am J Dermatopathol 1989;11:353-359.

257 Lyon JB, Rouillard LM. Malignant degeneration of turban tumor of the scalp. Trans St John's Hosp Dermatol Soc 1961;46:74-77.

258 Grouls V, Iwaszkiewicz J, Berndt R. Malignant dermal cylindroma. Pathologe 1991;12:157-160.

259 Dabska M. Malignant transformation of eccrine spiradenoma. Pol Med J 1972;11:388-396.

260 Evans HL, Su WPD, Smith JL, et al. Carcinoma arising in eccrine spiradenoma. Cancer 1979;43: 1881-1884. 
261 Cooper PH, Frierson Jr HF, Morrison AG. Malignant transformation of eccrine spiradenoma. Arch Dermatol 1985;121:1445-1448.

262 Wick MR, Kaye VN, Swanson PE, et al. Sweat gland carcinoma ex eccrine spiradenoma. Am J Dermatopathol 1987;9:90-98.

263 Argenyi AZ, Nguyen AV, Balogh K, et al. Malignant eccrine spiradenoma: a clinicopathologic study. Am J Dermatopathol 1990;12:335-343.

264 Varsa EW, Jordan SW. Fine needle aspiration cytology of malignant spiradenoma arising in congenital eccrine spiradenoma. Acta Cytol 1990;34:275-277.

265 Zamboni AC, Zamboni WA, Ross DS. Malignant eccrine spiradenoma of the hand. J Surg Oncol 1990;43:131-133.

266 Yaremchuk MJ, Elias LS, Graham RR, et al. Sweat gland carcinoma of the hand: two cases of malignant eccrine spiradenoma. J Hand Surg 1984;9:910-914.

267 McKee PH, Fletcher CD, Rasbridge SA. The enigmatic eccrine epithelioma (eccrine syringomatous carcinoma). Am J Dermatopathol 1990;12:552-561.

268 Pizinger K, Michal M. Malignant cylindroma in Brooke-Spiegler syndrome. Dermatology 2000;201: 255-257.

269 Jamshidi M, Nowak MA, Chiu YT, et al. Giant malignant eccrine spiradenoma of the scalp. Dermatol Surg 1999;25:45-48.

270 Brownstein MH, Helwig EB. Metastatic tumors of the skin. Cancer 1972;29:1298-1307.

271 Brownstein $\mathrm{MH}$, Helwig EB. Patterns of cutaneous metastasis. Arch Dermatol 1972;105:862-868.

272 Wick MR, Goellner JR, Wolfe III JT, et al. Adnexal carcinomas of the skin: I. Eccrine carcinomas. Cancer 1985;56:1147-1162.

273 El-Domeiri AA, Brasfield RD, Huvos AG, et al. Sweat gland carcinoma: a clinicopathologic study of 83 patients. Ann Surg 1971;173:270-274.

274 Kay S, Hall WEB. Sweat gland carcinoma with proved metastases. Cancer 1954;7:373-376.

275 Okada N, Ota J, Sato K, et al. Metastasizing sweat gland carcinoma. Arch Dermatol 1984;120:768-769.

276 Miller WL. Sweat gland carcinoma: a clinicopathologic problem. Am J Clin Pathol 1967;47:767-780.

277 Swanson PE, Mazoujian G, Mills SE, et al. Immunoreactivity for estrogen receptor protein in sweat gland tumors. Am J Surg Pathol 1991;15:835-841.

278 Swanson PE, Wick MR. Immunohistochemistry of cutaneous tumors. In: Leong ASY (ed). Applied Immunohistochemistry for the Surgical Pathologist. Edward Arnold: London, 1993, pp 269-308.

279 Wong TY, Suster S, Nogita T, et al. Clear cell eccrine carcinomas of the skin: a clinicopathologic study of nine patients. Cancer 1994;73:1631-1643.

280 Suster S. Clear cell tumors of the skin. Semin Diagn Pathol 1996;13:40-59.

281 Headington JT, Niederhuber JE, Beals TF. Malignant clear cell acrospiroma. Cancer 1978;41:641-647.

282 Kersting DW. Clear cell hidradenoma and hidradenocarcinoma. Arch Dermatol 1963;87:323-333.

283 Keasbey LE, Hadley GG. Clear cell hidradenoma: report of three cases with widespread metastases. Cancer 1954;7:934-952.

284 McKenzie DH. A clear-cell hidradenocarcinoma with metastases. Cancer 1957;10:1021-1023.

285 Chung CK, Hefferman AH. Clear cell hidradenoma with metastasis. Plast Reconstr Surg 1971;48: 177-179.
286 Czarnecki DB, Aarous I, Dowling JP. Malignant clear cell hidradenoma: a case report. Acata Dermatol Venereol 1982;62:173-176.

287 Hernandez-Perez E, Cestoni-Parducci R. Nodular hidradenoma and hidradenocarcinoma: a 10 year review. J Am Acad Dermatol 1985;12:15-20.

288 Kwon TJ, Ro JY, Mackay B. Clear-cell carcinoma: an ultrastructural study of 57 tumors from various sites. Ultrastruct Pathol 1996;20:519-527.

289 Tolia BM, Whitmore WF. Solitary metastasis from renal cell carcinoma. J Urol 1975;114:836-838.

290 Connor DH, Taylor HB, Helwig EB. Cutaneous metastases of renal cell carcinoma. Arch Pathol 1963;76:339-346.

291 Sharvill DE. Mixed salivary-type tumor of the skin with malignant recurrence. Br J Dermatol 1962;74: 103-104.

292 Rosborough D. Malignant mixed tumors of the skin. Br J Surg 1963;50:697-699.

293 Matz LR, McCully DJ, Stokes BAR. Metastasizing chondroid syringoma: a case report. Pathology 1961;1:77-81.

294 Hilton JMN, Blackwell JB. Metastasizing chondroid syringoma. J Pathol 1972;109:167-170.

295 Webb JN, Stott WG. Malignant chondroid syringoma of the thigh. J Pathol 1975;116:43-46.

296 Botha JBC, Kahn LB. Aggressive chondroid syringoma. Arch Dermatol 1978;114:954-955.

297 Ishimura E, Iwamoto H, Kobashi Y, et al. Malignant chondroid syringoma. Report of a case with widespread metastasis and review of pertinent literature. Cancer 1983;52:1966-1973.

298 Scott A, Metcalf S. Cutaneous malignant mixed tumor. Am J Dermatopathol 1988;10:335-342.

299 Shvili D, Rothem A. Fulminant metastasizing chondroid syringoma of the skin. Am J Dermatopathol 1986;8:321-325.

300 Harrist TJ, Aretz TH, Mihm Jr MC, et al. Cutaneous malignant mixed tumor. Arch Dermatol 1981;117: 719-724.

301 Pinto de Moraes H, Herrera GA, Mendonca AM, et al. Metastatic malignant mixed tumor of the skin: ultrastructural and immunohistochemical characterization, histogenetic considerations, and comparison with benign mixed tumors of skin and salivary glands. Appl Pathol 1986;4:199-208.

302 Redono C, Rocamora A, Villoria F, et al. Malignant mixed tumor of the skin: malignant chondroid syringoma. Cancer 1982;49:1690-1696.

303 De Francesco V, Frattasio A, Pillon B, et al. Carcinosarcoma arising in a patient with multiple cylindromas. Am J Dermatopathol 2005;27:21-26.

304 Wick MR, Swanson PE. 'Carcinosarcomas'current perspectives and a historical review of nosological concepts. Semin Diagn Pathol 1993;10: 118-127.

305 Wick MR, Coffin CM. Sweat glands and pilar carcinomas. In: Wick MR (ed). Pathology of Unusual Malignant Cutaneous Tumors. Marcel-Dekker: New York, 1985, pp 1-76.

306 Toker C. Trabecular carcinoma of the skin. Arch Dermatol 1972;105:107-110.

307 Busam DJ, Gellis S, Shimamura A, et al. Small cell sweat gland carcinoma in childhood. Am J Surg Pathol 1998;22:215-220.

308 Crowson AN, Magro CM, Mihm Jr MC. The Melanocytic Proliferations: A Comprehensive Textbook of 
Pigmented Lesions. John Wiley and Sons: New York, 2001.

309 Jones RE, Ackerman AB. Extramammary Paget's disease: a critical reappraisal. Am J Dermatopathol 1979;1:101-132.

310 Kuan SF, Montag AG, Hart J, et al. Differential expression of mucin genes in mammary and extramammary Paget's disease. Am J Surg Pathol 2001;25: 1469-1477.

311 Jones RE. Mammary Paget's disease without underlying carcinoma. Am J Dermatopathol 1985;7: 361-365.

312 Mori O, Hachisuka H, Nakano S, et al. A case of mammary Paget's disease without an underlying carcinoma: microscopic analysis of the DNA content in Paget cells. J Dermatol 1994;21:160-165.

313 Willman JH, Golitz LE, Fitzpatrick JE. Vulvar clear cells of Toker. Precursors of extramammary Paget's disease. Am J Dermatopathol 2005;27:185-188.

314 Honda Y, Egawa K. Extramammary Paget's disease not only mimicking but also accompanying condyloma accuminatum. Dermatology 2005;210:315-318.

315 Lee SC, Roth LM, Ehrlich C, et al. Extramammary Paget's disease of the vulva: a clinicopathologic study of 13 cases. Cancer 1977;39:2540-2549.

316 Boehm F, Morris JML. Paget's disease and apocrine gland carcinoma of the vulva. Obster Gynecol 1971;38:185-192.

317 Hart WR, Millman JB. Progression of intraepithelial Paget's disease of the vulva to invasive carcinoma. Cancer 1977;40:2333-2337.

318 Mitsudo S, Nakanishi I, Koss LG. Paget's disease of the penis and adjacent skin: its association with fatal sweat gland carcinoma. Arch Pathol Lab Med 1981;105:518-520.

319 Knauer Jr WJ, Whorton CM. Extramammary Paget's disease originating in Mill's glands of the eyelid. Trans Am Acad Ophthalmol Otolaryngol 1963;67: 829-833.

320 Nadji M, Morales AR, Girtanner RE, et al. Paget's disease of the skin: a unifying concept of histogenesis. Cancer 1982;50:2203-2206.

321 Rayne SC, Santa Cruz DJ. Anaplastic Paget's disease. Am J Surg Pathol 1992;16:1085-1091.

322 Mazoujian G, Pinkus GS, Haagensen DE. Extramammary Paget's disease: evidence for an apocrine origin. Am J Surg Pathol 1984;8:43-50.

323 Satoh F, Umemura S, Osamura RY. Immunohistochemical analysis of GCDFP-15 and GCDFP-24 in mammary and non-mammary tissue. Breast Cancer 2000;7:49-55.

324 Kariniemi AL, Ramaekers F, Lehto VP, et al. Paget cells express cytokeratins typical of glandular epithelia. Br J Dermatol 1985;112:179-183.

325 Hitchcock A, Topham S, Bell J, et al. Routine diagnosis of mammary Paget's disease. Am J Surg Pathol 1992;16:58-61.

326 Helm KF, Goellner JR, Peters MS. Immunohistochemical stains in extramammary Paget's disease. Am J Dermatopathol 1992;14:402-407.

327 Liegl B, Horn LC, Moinfar F. Androgen receptors are frequently expressed in mammary and extramammary Paget's disease. Mod Pathol 2005; May 13 (Epub ahead of print).

328 Reich O, Liegl B, Tamussino K, et al. P185HER2 overexpression and HER2 oncogene amplification in recurrent vulvar Paget's disease. Mod Pathol 2005;18:354-357.

329 Brummer O, Stegner HE, Bohmer G, et al. HER-2/neu expression in Paget's disease of the vulva and female breast. Gynecol Oncol 2004;95:336-340.

330 Takeshita K, Kzumoi S, Ebuchi M, et al. A case of rectal carcinoma concomitant with pagetoid lesion in the perianal region. Gastroenterol Jpn 1978;13: 85-95.

331 McKee PH, Hertogs KT. Endocervical adenocarcinoma and vulvar Paget's disease: a significant association. Br J Dermatol 1980;103:443-448.

332 Degefu S, O'Quinn AG, Dhurandhar HN. Paget's disease of the vulva and urogenital malignancies. Gynecol Oncol 1986;25:347-354.

333 Ojeda VJ, Heenen PJ, Watson SH. Paget's disease of the groin associated with adenocarcinoma of the urinary bladder. J Cutan Pathol 1987;14:227-231.

334 Fujimoto A, Takata M, Hatta N, et al. Expression of structurally unaltered androgen receptor in extramammary Paget's disease. Lab Invest 2000;80:14651471.

335 Diaz-de-Leon E, Carcangiu ML, Prieto VG, et al. Extramammary Paget disease is characterized by the consistent lack of estrogen and progesterone receptors but frequently expresses androgen receptor. Am J Clin Pathol 2000;113:572-575.

336 Soini Y. Claudins 2,3,4 and 5 in Paget's disease and breast carcinoma. Hum Pathol 2004;35:1531-1536.

337 Bogner PN, Su LD, Fullen DR. Cluster designation 5 staining of normal and non-lymphoid neoplastic skin. J Cutan Pathol 2005;32:50-54. 